\title{
TOCADOR Y BIOMBO EN LOS INTERIORES DOMÉSTICOS EN EL BURGOS DEL SETECIENTOS: MOBILIARIO PARA LA VANIDAD
}

\author{
Dressing Table and Screen in Domestic Interiors in Burgos \\ in Eighteenth Century: Furniture for Vanity
}

\author{
Francisco J. Sanz de la Higuera \\ sanzdelahiguera@gmail.com \\ profesor EEMM jubilado. España \\ Fecha de recepción: 09/06/2019 \\ Fecha de aceptación: 30/10/2019
}

RESUMEN: En un reducido volumen de hogares de la ciudad de Burgos, sus titulares disponían de un mobiliario caracterizado por su notable exclusividad. Se trata de la presencia, en sus interiores domésticos, de tocadores, cómodas y biombos. Descubrimos el tocador en el $7.7 \%$ de los inventarios recopilados. El biombo en, únicamente, el $4.5 \%$. Si tenemos en cuenta que el canapé había sido aclimatado en sus estancias en el $9 \%$ de las viviendas y que un refinamiento tan curioso como "Una mesa para comer y cenar en la cama» solo aparece en el $5.6 \%$, nos proponemos efectuar una reconstrucción histórica sobre enseres marcados por la diferencialidad, materializada en hogares dados a la búsqueda de notoriedad, comodidad y confort y, quizá, martirizados por la tiranía de la moda.

Palabras clave: Tocador; biombo; interiores domésticos; Burgos; siglo XVIII.

ABSTRACT: In a little number of homes in the city of Burgos, its owners had furniture characterized by its remarkable exclusivity. It is about the presence, in their domestic interiors, of dressing tables, chests of drawers and folding screens. We find the dressers in $7.7 \%$ of the inventories collected. The screen in, only, $4.5 \%$. If we take into account that the couch, had been included in the rooms of $9 \%$ of the houses and that such a curious refinement as "A table for lunch and dinner in bed» only appears in $5.6 \%$, we intend to carry out a historical reconstruction on items marked by singularity, materialized in homes given to the search for notoriety, comfort and, perhaps, tormented by the tyranny of fashion.

Keywords: Dressing table; screen; domestic interiors; Burgos; 18th century. 
SUMARIO: 1. Introducción, fuentes documentales y aproximación bibliográfica. 2. Presencia de tocador y biombo en los hogares de Burgos en el XVIII. 3. Valoración económica del tocador y del biombo. 4. Las maderas del tocador. 5. Ubicación del tocador y el biombo en los interiores domésticos. 6. Cuantificación del número de tocadores y biombos. 7. ¿Tocador y biombo simultáneamente? 8 . A modo de conclusión. 9. Referencias bibliográficas.

\section{INTRODUCCIÓN, FUENTES DOCUMENTALES Y APROXIMACIÓN BIBLIOGRÁFICA}

Los hogares burgaleses del Setecientos disponían sus viviendas de forma que satisfacían, en la medida de lo posible, sus ansias de "habitabilidad, domesticidad y sociabilidad» (Franco Rubio, 2009; 2012). Para ello, de puertas adentro (Dos Guimaraes y García Fernández, 2010; García Fernández, 2012), preñaban sus estancias con múltiples enseres y pertrechos, en especial con diferentes tipos de mobiliario. No todos pudieron llevarlo a la práctica de la misma forma, ni en calidad ni en cantidad. Nos topamos, en la práctica, con muebles para reposar en lo nocturno, para guardar y proteger, para tomar asiento y comer, para cocinar o para trabajar. Lo usual era acomodar mesas, sillas, taburetes, camas, catres, cujas, arcas, arcones, baúles... Empero, entre los muebles para contener -a la postre, para guardar y proteger-, descuella el tocador y solo unos pocos pudieron acceder a su disfrute. El tocador es uno de los vórtices más significativo de las «nuevas maneras» que se aclimataron en el siglo XVIII, lejos de "la rigidez de la postura y del comportamiento, derivadas de la concepción estamental de las relaciones sociales, a favor de actitudes más libres, vinculadas a la espontaneidad y el desembarazo de los movimientos, y a la naturalidad del trato propias de la burguesía emergente» (Rodríguez Bernis, 2009). Era imprescindible imitar, emular (Ramos Palencia, 2016), las costumbres europeas $y$, en concreto, la «francesa de admitir a los íntimos en el gabinete donde se hallaba el tocador, a la hora del vestido y del peinado» (Rodríguez Bernis, 2009, p. 40). Empero, también, se deseaba profundizar, para multiplicar el confort, en el grado de intimidad personal. El biombo ayudó en esta estrategia, al disponer, de una forma muy dúctil y articular, de "paredes» móviles que evitaban miradas indiscretas en el seno de las propias estancias domésticas. Lo que, en principio, era su «objetivo originariamente (...) la protección contra las corrientes de aire -la palabra japonesa de la que procede el término biombo se puede traducir como "pantalla de protección contra el viento" - acabó derivando, con el tiempo, en otra función principal, la de la separación de ambientes en una estancia» (Sánchez-Cascado, 2019)1.

La calidad de la fuente documental marca la trascendencia de los análisis posibles. Lamentablemente no todos los apuntes de los escribanos tuvieron el mismo

\footnotetext{
${ }^{1}$ Véanse también Arimura, 2007; Curiel, 1999 y González Heras, 2014.
} 
puntillismo a la hora de considerar la presencia del tocador en las casas burgalesas ${ }^{2}$. La mayoría adolecen de un detenimiento pormenorizado en la descripción de la estancia en que ubicaba y la madera y las medidas del mueble. Disponemos, por fortuna, de dos inventarios en que se dan todas ellas simultáneamente. En primera instancia, la vivienda del noble rentista Ciriaco Luís Zorrilla Barrenechea. En el "Quarto pintado o Tocador» se documenta la disponibilidad de "Un tocador de Caoba [con] filete dorado, y dos Nabetas al pie con su Espejo, de cerca de media vara de largo [0.41 metros] y una quarta de ancho [0.20 metros]» -tasado en 150 reales de vellón ${ }^{3}$. En segundo término, las anotaciones del escribano en la casa-mansión del marqués de Villacampo. En el "Quarto Estrado del lado de la calle» se había dispuesto "Un tocador de media vara de largo [0.41 metros] y más de tercia de ancho [0.20 metros], embutido en ébano, Concha y hueso, con Zerradura y llave» (130 reales) ${ }^{4}$. En otros inventarios se alcanza casi la perfección, pero falla la determinación de las medidas. Por ejemplo, en el inventario post-mortem del mercader de paños y sedas Gregorio Bernáldez de Velasco. En el «Quarto pequeño» encontramos "Un tocador de Zedro Con dos navetillas, Zerradura y llaves, y sobre él Un espexo, Con su guarnizión de Vidrio, Colunas y adorno dorado, y aquellas pintadas y doradas» (55 reales) y en el "Quarto segundo» «Un tocador de Nogal y concha Con dos navetas» (70 reales) $)^{5}$. En el post-mortem de Juan Manuel Carrillo, regidor perpetuo en Burgos, se describe "Un tocador de Hevano de dos tercias de altto [0.55 metros] y dos de ancho [0.55 metros] con onze Navettas, las Diez bordadas de Ylo de plata y la ottra Chapiada de Hebano con una puerttecilla en medio, y un Cupido con Cinco espejos y en la tapa de arriva ottro en quadro" (400 reales) ${ }^{6}$, pero se nos hurta la estancia de su ubicación $n^{7}$. El tocador es un mueble de lujo, en el que "se llevaba a cabo el "diario y complicado" arreglo personal de los miembros de la familia; allí se cortaban el pelo, lavaban, perfumaban y acicalaban» (Curiel, 2005; Moreyra, 2009).

Para generar esta reconstrucción histórica se ha conseguido recopilar 924 inventarios de bienes, la mayoría de los cuales proceden de los legajos custodiados en el Archivo Histórico Provincial de Burgos ${ }^{8}$. Son muchas las virtudes, pero también

2 Sobre la significación de estancias o no en los inventarios de bienes: Sobrado Correa, 2003.

${ }^{3}$ Archivo Histórico Provincial de Burgos. Protocolos Notariales (en lo sucesivo AHPB. PN). Miguel Palma Valderrama. Legajo 7288 (18 de junio de 1796), folio141r.

${ }^{4}$ AHPB. PN. José Guadilla. Legajo 7133/1 (11 de enero de 1788), folio 56v.

${ }^{5}$ AHPB. PN. José Guadilla. Legajo 7131 (4 de enero de 1776), folios 254v y 256v.

${ }^{6}$ Este tocador llevaba aparejada "Una Mesita (...) de pino dada de negro, qe su tasación esttá incluida en la partida antecedente».

7 AHPB. PN. Jacinto del Río. Legajo 7054/3 (3 de noviembre de 1756), folio 368.

8 El $94 \%$ de los inventarios proceden del Archivo Histórico Provincial de Burgos. Protocolos Notariales (AHPB. PN). El $3.1 \%$ de AHPB. Justicia Municipal (JM). El 1.2 \% del Archivo Capitular de 
los defectos que se pueden argumentar sobre dicha fuente documental (Ramos Palencia, 2010)9. En historia hemos de combatir, constantemente, con la problemática de la representatividad y con la necesidad de generar fórmulas de autenticación de la realidad pretérita que posibiliten hacer creíbles los análisis que se formulan.

El acervo bibliográfico al que tenemos acceso nos ayuda, en la medida de lo posible, en la imprescindible búsqueda de contrastes con otras localidades, circunstancias y ocurrencias en el devenir del Setecientos. Los "yacimientos» documentales y bibliográficos constituyen herramientas esenciales para la reconstrucción del acontecer histórico. Descuellan con luz propia, citadas sin ánimo de exhaustividad ni la pretensión de efectuar un estado de la cuestión, las aportaciones elaboradas -con apuntes en los que se trata, con mayor o menor detenimiento, el tocador y el biombo- por Piera Miquel (2009a; 2006; 2009b; 2009c; 2019), Rodríguez Bernis (2009, p. 40; 2010), Abad Zardoya (2004; 2007), Martínez Alcázar (2008; 2011), López Castán (2004), Ortego Agustín (2009), González Heras (2014) , Mateos Gil (2007), Nadal Iniesta (2006), Pardailhé-Galabrun (1988), Ordóñez Poded (2016, pp. 232, 250, 279, 391-392 y 423-426), Madureira (1992), Angulo Morales (2000), García Fernández (2016), Ramos Palencia (2010), Bartolomé Bartolomé (2017), Blasco Esquivias (2006), Curiel (1999, pp. 9-32; 2005), Pichardo Hernández (2009), Baena Zapatero (2007; 2015), Crespo Rodríguez (2006), López Pérez (1999) o Ette (2014). Se echa de menos mención al tocador o el biombo en algunas de las grandes obras sobre cultura material ${ }^{10}$.

\section{PRESENCIA DE TOCADOR Y BIOMBO EN LOS HOGARES DE BURGOS EN EL SIGLO XVIII}

El tocador, «boudoir» o "toilette» ${ }^{11}$, es una mesa con espejo y otros adornos, indicado para el aseo y el peinado. El tocador es una «Caja de madera exquisita con algunos embutidos de concha o marfil o plata y en ella divisiones para guardar los adornos y bujerías del tocado de las mujeres. Suelen tener en la tapa un espejo,

la Catedral de Burgos (ACCB). EL $1 \%$ del Archivo Municipal de Burgos (AMB). El $0.4 \%$ del Archivo General de Palacio (Madrid) (AGP). El $0.2 \%$ del Archivo de la Diputación Provincial de Burgos. Fondo Berberana (ADPB) y el $0.1 \%$ del Archivo Diocesano de Burgos. San Lesmes (ADB).

9 también, entre otras muchas opciones, las reflexiones de Sobrado Correa, 2003; Álvarez Santaló y García-Baquero García, 1980; Franch Benavent, 1989; Pardailhé-Galabrun, 1988; Yun Casalilla, 1999 o Moreno Claverías, 2007.

10 Por ejemplo, entre las más eminentes, Sarti, 2002; Pounds, 1999 y Ago, 2006. Tampoco los encontramos en Waro-Desjardins, 1992, porque lo esencial es "La rareté des commodes et des horloges", p. 106.

${ }^{11}$ El tocador o kyodai en Ordóñez Poded, 2016, p. 250 y Choi, 2018. 
para estarse mirando cuando se peinan ${ }^{12}$. El tocador es un mueble parecido a una mesa de escritorio, pero más estrecho, provisto de un espejo y a menudo cajones, que sirve para el arreglo personal. También es una habitación destinada al arreglo personal, donde suele haber uno de estos muebles. Se trata de un galicismo introducido en España en el siglo XVIII. El canapé y la cómoda conocieron una suerte similar. El más rutilante de los encontrados en los inventarios de bienes de Burgos es el aparecido en la casa-mansión de María Fausta de la Gasca, "Un tocador de moda con su mesa, todo de Charol encarnado, su espejo enzima deel tocador, con marco de lo mismo, de dos terzias de largo [0.55 metros] y media vara de ancho [0.41 metros], poco más o menos, y la mesa con su cajón y la Luna con su funda de tafetán pajizo", tasado en 1.000 reales de vellón ${ }^{13}$. Descuella también el localizado en la vivienda del regidor perpetuo Lucas Francisco Castro y Ocio - Un tocador de granadillo con ocho Nichos y su espejo, con veinte piezas de platta y ocho Canttoneras de bronze dorado y su escudo de lo mismo y un niño encima, ttambién de lo mismo» (180 reales) ${ }^{14}$. "Il gusto delle cose ${ }^{15}$ va a estimularse en los hogares, con la búsqueda de mejoras en la cosmética y en el «afán de emulación de las capas sociales ascendentes que incorporaron el aseo en el tocador como práctica de individualismo en consonancia con el ideal burgúes, pero también imprescindible para la sociabilidad» (Ortego Agustín, 2009, pp. 82 y 91).

El tocador, en la inmensa mayoría de las ocasiones -en Burgos, el $98.6 \%$ de los hogares-, es un mueble ubicado en alguna de las estancias de la casa -en algunos casos en más de una. Empero, nos topamos con un $1.4 \%$ de hogares en que se denomina, de manera simultánea, tocador y a la estancia. En el inventario postmortem del noble rentista Ciriaco Luís Zorrilla Barrenechea se define la existencia de un "cuarto pintado o Tocador», en el que, además de un «Catre» y "una mesa de Nogal para juego embutida en Nacar, forrada de paño verde y Cubierta de CabretiIla, [con] pies de Cabra» -tasada en 500 reales de vellón-y varias sillas, se ubicaba el anteriormente citado "tocador de Caoba». En el cercano «Quarto pequeño de los Papeles» había ubicado otro "tocador con su paño de seda Azul por detrás con su espejo pequeño y Cubierta de Muselina ordinaria» (60 reales) ${ }^{16}$.

12 Diccionario de Autoridades (1726). Madrid: Real Academia de la Lengua.

${ }^{13}$ AHPB. PN. José Fernández Guilarte. Legajo 7004 (23 de febrero de 1734), folio 220v.

${ }^{14}$ AHPB. PN. Juan Antonio Fernández Guilarte. Legajo 7025 (5 de febrero de 1760), folio 86r. En el inventario post-mortem de su viuda, la tasación se redujo a 120 reales porque había perdido una de las 20 piezas. AHPB. JM. Juan Antonio Fernández Guilarte. Legajo 976 (6 de octubre de 1763), folio 9 r.

15 Según la emblemática expresión de Ago, 2006.

${ }^{16}$ AHPB. PN. Miguel Palma Valderrama. Legajo 7288 (18 de junio de 1796), folios 141r y $143 r$. 
El biombo, de origen oriental, "se utilizaba en diferentes habitaciones de la casa con el principal objetivo de separar u ocultar algo» (Ordóñez Goded, 2016, p. 391). Eran "elementos de prestigio» "las manufacturas asiáticas más apreciadas por la sociedad» (Ordóñez Goded, 2016, p. 232). Según señala González Heras, en compartimentaciones arquitectónicas con múltiples «aposentos de recepción de amplitud (...) [se] fomentaba el uso de muebles de exquisito gusto estético que permitieran crear apartados» (González Heras, 2014, p. 394).

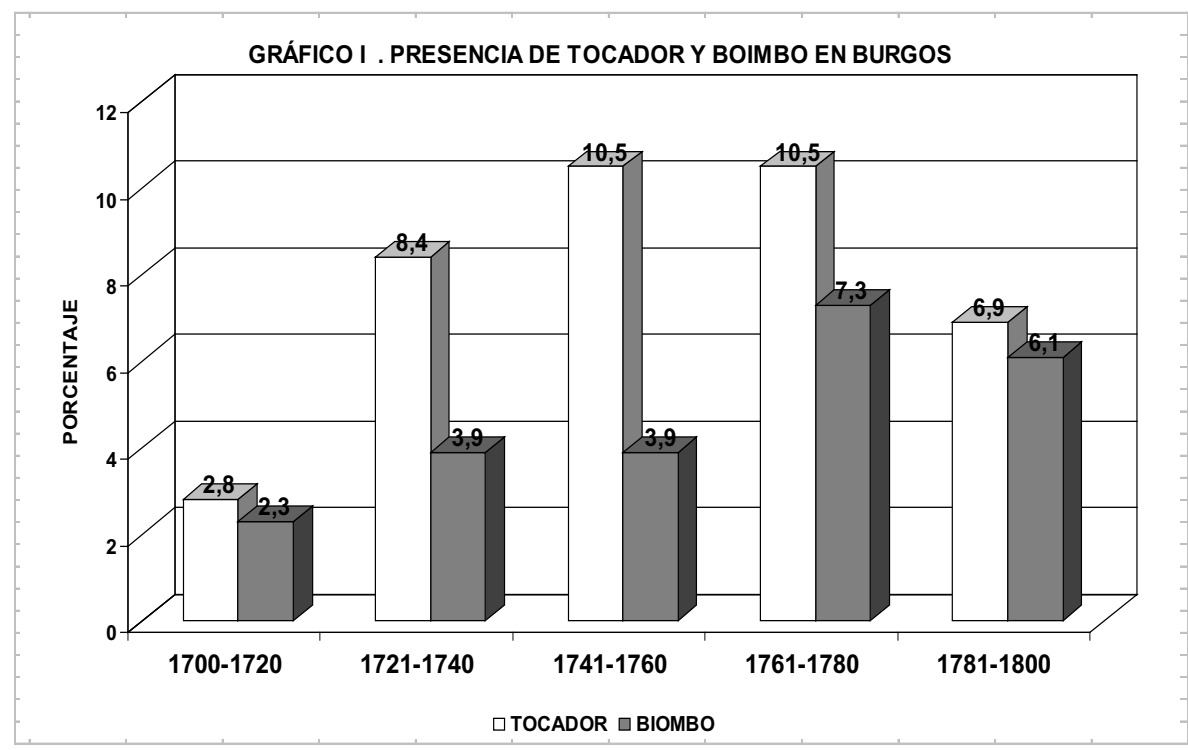

Fuente documental. AHPB. PN y otros Archivos. Múltiples Legajos (1700-1800).

El devenir de la presencia del tocador y el biombo en los interiores domésticos de las viviendas de Burgos en el siglo XVIII -GRÁFICO I- está sujeto, como ha quedado demostrado para otros muebles de prestigio y para la vanidad -en especial, el canapé (Sanz de la Higuera, 2013; 2019), como se demuestra en el GRÁFICO II-, a un progresivo afianzamiento y asimilación de su disfrute. En este sentido, Mantecón Movellán centra, de manera incuestionable, la problemática al señalar que «La cronología de los cambios en el gusto y en la preocupación de los compradores (...) muestra que es más que una revolución producida en el siglo XVIII lo que se experimentó, ya desde el XVII, fue un cambio que adoptó la forma de una evolución pausada, un efecto goteo en las direcciones apuntadas, acelerado, eso sí, en la segunda mitad del siglo XVIII y particularmente en las últimas tres décadas» (Mantecón Movellán, 2013). No se trata, a la postre, de una aclimatación vertiginosa sino, más bien, suave pero sostenida, aunque al final del siglo (1781-1800) se produce, en ambas magnitudes, un significativo deterioro de su presencia. 


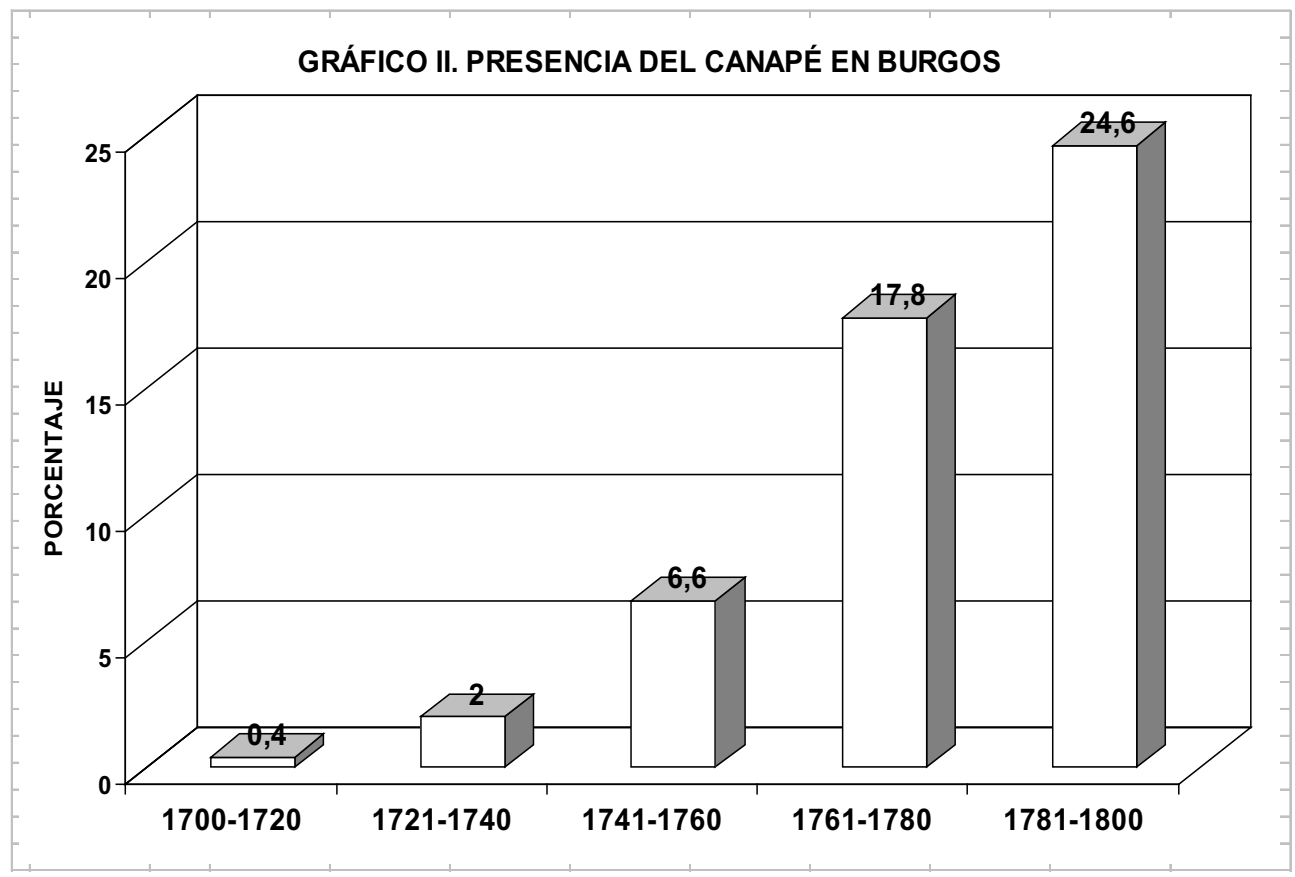

Fuente documental. AHPB. PN y otros Archivos. Múltiples Legajos (1700-1800).

No es baladí el considerar que en el orto del XVIII el tocador y el biombo no eran enseres usuales ni demasiado habituales en las casas burgalesas. De hecho, únicamente han sido hallados en menos del $3 \%$ de los inventarios -GRÁFICO I. Esta similitud casi pareja se desvía posteriormente con una trayectoria para el tocador más efervescente. En 1721-1740, el tocador se ha proyectado hasta el $8.4 \%$ mientras que el biombo llega con dificultad al $4 \%$. El biombo de estanca en el siguiente segmento temporal (1741-1760). El tocador, empero, se dispara hasta el $10.5 \%$, cifra en la que se instala cómodamente en el siguiente estadio (1761-1780). El biombo, no obstante, casi duplica su presencia en ese instante. Ambos alcanzan su máximo «techo» de asimilación hacia 1780 y, como se ha advertido, en 1781-1800 se precipitan a porcentajes del 6-7\%. Resulta evidente que su prestigio y su disfrute sufrió un poderoso retroceso en las casas burgalesas de finales del XVIII. El primer tocador del que tenemos constancia en el Burgos del Setecientos es el documentado en casa de Francisco Crespo Pérez en $1705^{17}$. La primera aparición de un biombo procede del inventario de Francisca Vélez Mansilla, viuda de Francisco Zárate Ladrón de Guevara, oidor de la Chancillería de Valladolid y miembro del Consejo de Su Majestad $^{18}$.

17 AHPB. PN. Manuel García Ruiz. Legajo 6912 (31 de marzo de 1705), 49r.

${ }^{18}$ AHPB. PN. Agustín García Manrique. Legajo 6799 (26 de enero de 1701), folio 619v. 


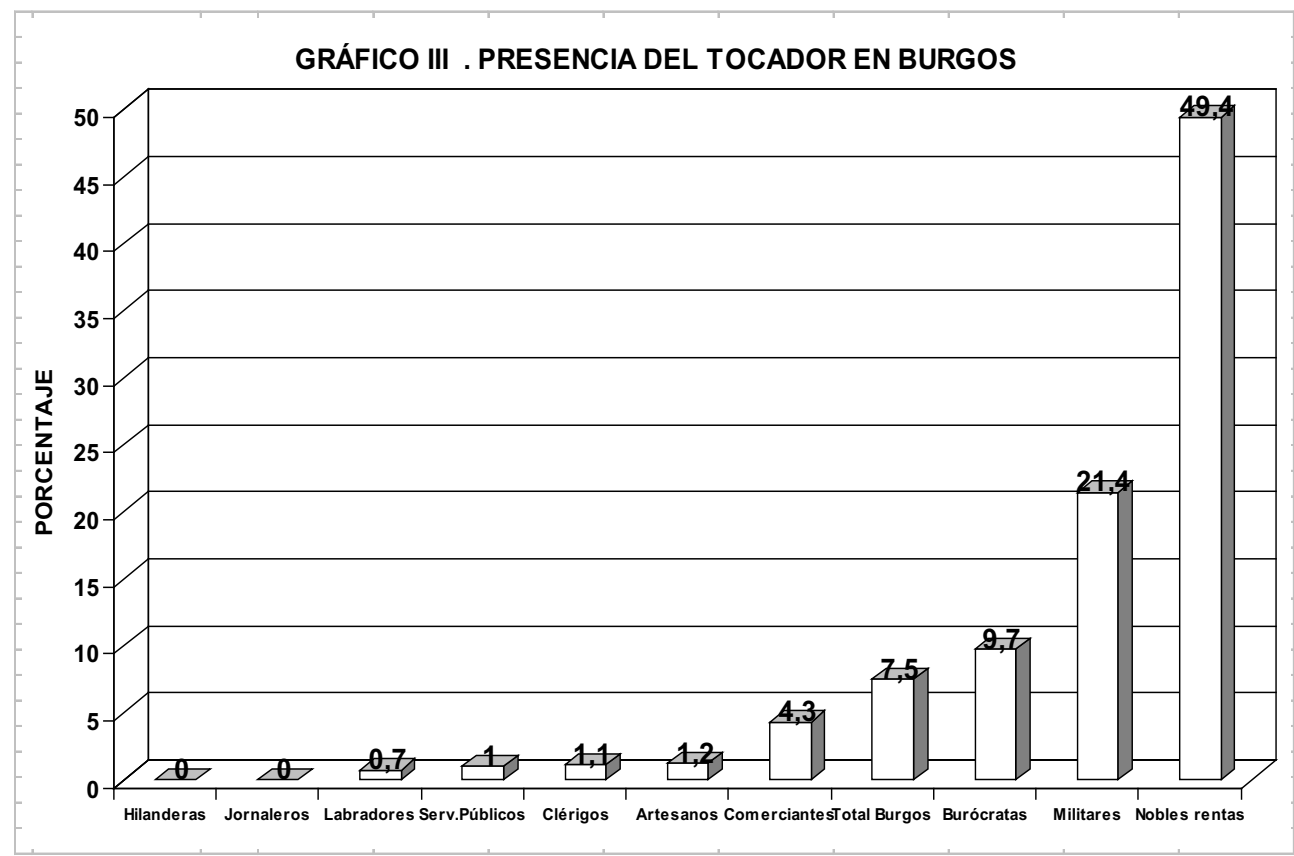

Fuente documental. AHPB. PN y otros Archivos. Múltiples Legajos (1700-1800)

La presencia del tocador no fue homogénea en todos los hogares de Burgos. Se descubren, a mi entender, cuatro situaciones diferentes -GRÁFICO III. En primera instancia, la de las categorías socio-profesionales que, en ningún caso, conocieron en el interior de sus estancias tocador alguno. Tampoco disponían de reloj, canapé, etcétera. Las hilanderas y los pobres de solemnidad y los jornaleros no disfrutaron en ningún momento del Setecientos de ellos. Se trata, sin duda, de aquellos hogares resignados a "consumir poco de poco" (Moreno Claverías, 2003). Son los "pobres sin [apenas] mobiliario», según enfatizó Braudel (1984). En segundo término, con índices de presencia del tocador por debajo del $2 \%$, labradores y hortelanos, profesionales de los servicios públicos ${ }^{19}$, clérigos y maestros y oficiales artesanos. En tercer lugar, comerciante ${ }^{20}$ y burócratas ${ }^{21}$, clasificables como hogares que consumían mucho de poco (Moreno Claverías, 2003, nota 3, pp. 225-230). En última instancia,

${ }^{19}$ Hogares implicados en la gestión de mesones y casas de posada, sanidad y salud pública -médicos, boticarios, farmacéuticos, cirujanos, barberos...-, obligados de la logística municipal -carnes, carbón, pescado, aloja...-... géneros.

${ }^{20}$ Mercaderes al por mayor, de paños y sedas, y mercaderes al por menor, de joyería y otros

21 Escribanos del número, procuradores del número y abogados, profesionales de las Administración de la hacienda borbónica ( $R$ Rentas Reales») y empleados en las Administraciones eclesiásticas (Audiencia arzobispal, Santa Cruzada...). 
los militares ${ }^{22}$ con el $21.4 \%$ y los nobles rentistas ${ }^{23}$ con el $49.4 \%$-, dados a consumir «mucho de mucho» (Moreno Claverías, 2003, nota 54, pp. 237-240).

\begin{tabular}{|c|c|c|c|c|c|c|}
\hline CUADRO I & \multicolumn{6}{|c|}{ Evolución de la presencia de tocador en los hogares de Burgos (\%) } \\
\hline & $1700-1720$ & $1721-1740$ & $1741-1760$ & $1761-1780$ & $1781-1800$ & Total \\
\hline Hilanderas & 0 & 0 & 0 & 0 & 0 & 0 \\
\hline Jormaleros & 0 & 0 & 0 & 0 & 0 & 0 \\
\hline Labradores & 0 & 5 & 0 & 0 & 0 & 0.7 \\
\hline Artesanos & 0 & 0 & 3.4 & 0 & 2.4 & 1.2 \\
\hline Comerciantes & 0 & 0 & 6.7 & 10.5 & 5 & 4.3 \\
\hline Burócratas & 2.7 & 10.3 & 20.7 & 8.3 & 7.7 & 9.7 \\
\hline Serv. Públicos & 0 & 0 & 6.2 & 0 & 0 & 1 \\
\hline Nobles rentistas & 20.8 & 50 & 69.2 & 81.2 & 42.8 & 49.4 \\
\hline Clérigos & 0 & 0 & 0 & 6.7 & 0 & 1.1 \\
\hline Militares & 0 & 50 & 25 & 33.3 & 0 & 21.4 \\
\hline \multicolumn{2}{|c|}{ Fuente documental: AHPB y otros Archivos. Múltiples Legajos (924 documentos). } & \\
\hline
\end{tabular}

Estos gruesos números no han de enmascarar que el devenir de la presencia del tocador tuvo diferentes momentos a lo largo de la centuria -CUADRO I. Los labradores y hortelanos únicamente aparecen en una ocasión, en 1721-1740. La presencia del tocador implicó exclusivamente a un campesino, José Díez - Un tocador con franxa de seda negra", heredado de su madre, tasado en 22 reales de vellón ${ }^{24}$. Algo similar, aunque más tardíamente (1741-1760), ocurre con Manuel Pérez de Límpias, boticario del Hospital del Rey, quien al fallecer era poseedor de «Un tocador con embutidos de ébano y marfil [y] cerradura de plata», evaluado en 200 reales ${ }^{25}$. En el segmento temporal 1761-1780 falleció el único clérigo que disfrutó de un tocador en sus estancias. Se trata de Manuel Salamanca Cerezo, beneficiado en la parroquia de San Lesmes - "Un tocador de Nogal de media bara de largo por tres cuartas de ancho con embutidos de Concha y palo Santo con Zerradura y llave» (60 reales de vellón) ${ }^{26}$. Los artesanos afloran de forma tardía, escasa, irregular y menguante.

22 Mandos militares -coronel, capitán, sargento mayor...- y tropas -sargento, cabo y soldado.

${ }^{23}$ Alcalde y regidores perpetuos del Consejo, terratenientes y titulados, rentistas de mayorazgos...

${ }^{24}$ AHPB. PN. Martín Robredo. Legajo 6970 (26 de mayo de 1730), folio 218r.

25 AHPB. PN. Gaspar Tomé González. Legajo 8311 (25 de septiembre de 1758), folio 53r.

${ }^{26}$ AHPB. JM. Alonso Melo Peña. Legajo 987 (23 de octubre de 1773), folio 3v. 


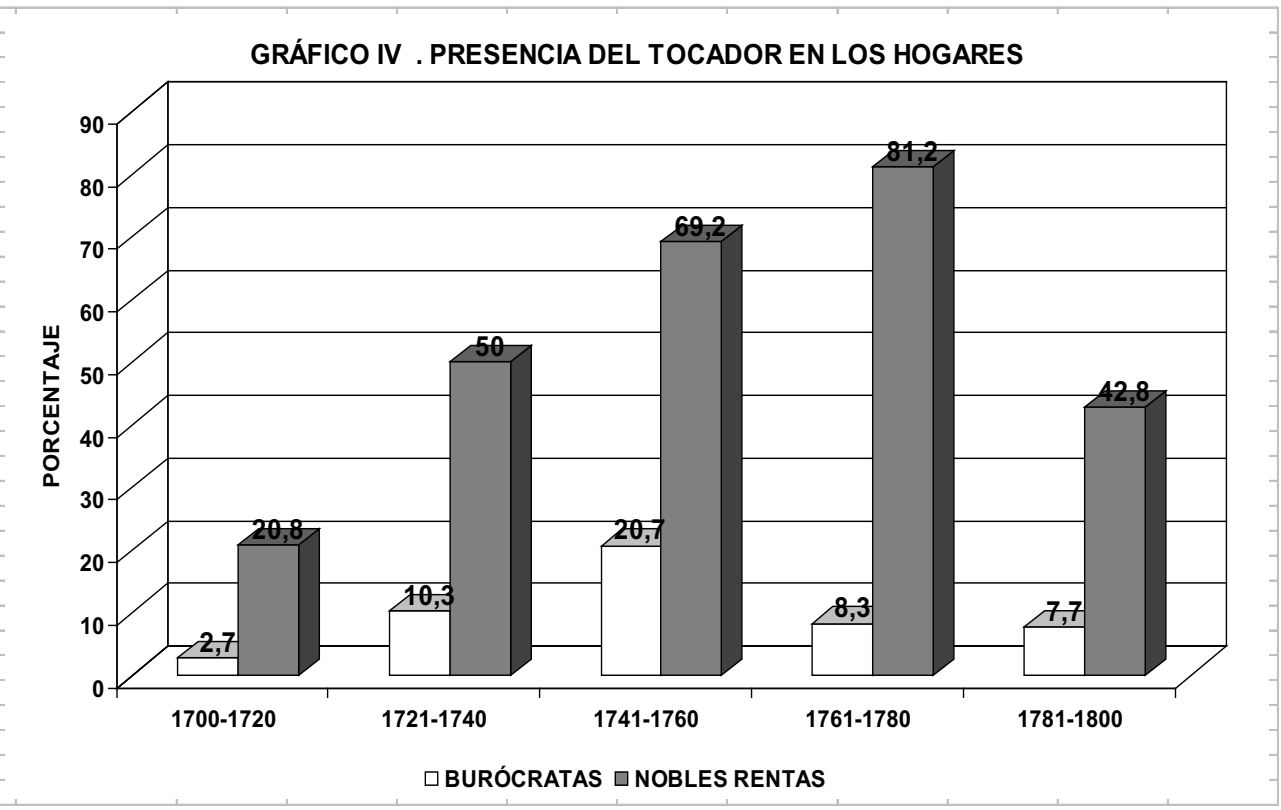

Fuente documental. AHPB. PN y otros Archivos. Múltiples Legajos (1700-1800).

Los comerciantes no disfrutaron de este mueble en fechas avanzadas -en los primeros 40 años del siglo no se detecta ninguno en sus casas. A partir de 1740 , la presencia del tocador es tímida (6.7\%) pero creciente $(10.5 \%)$, aunque al final del siglo menguó bastante (5\%). Los burócratas, como los nobles rentistas, se dejan ver a lo largo de la totalidad del Setecientos -GRÁFICO IV. Los primeros inician la centuria con una presencia muy reducida $(2.7 \%)$, crecen de manera sostenida, hasta el $10.3 \%$ (1721-1740) y el $20.7 \%$ (1741-1760), pero después se advierte un significativo decrecimiento en los últimos 40 años -hasta alrededor del $8 \%$. Los aristócratas urbanos dispusieron del tocador en sus casas con índices muy elevados. En todos los segmentos temporales, sus índices de presencia fueron, con mucho, los más sobresalientes $^{27}$, desde el $20.8 \%$ de $1700-1720$ hasta el $50 \%$ en $1721-1740$, el $69.2 \%$ de $1741-1760$ y el mayúsculo $81.2 \%$ de 1761-1780. En 1781-1800, se desplomó su presencia por debajo del $43 \%$. La edad dorada del tocador finiquitó con los estertores del XVIII. En último término, para los militares hemos hallado una trayectoria extraña ${ }^{28}$. Ninguna presencia en $1700-1721$ y $1781-1800$, un $50 \%$ en 1721-1740, un $25 \%$ en 1741-1761, un $33.3 \%$ en 1761-1780. El tocador, y la cómoda son, como sucede en la sociedad catalana del siglo XVIII, «bienes de lujo (...) símbolos del nivel social y económico de su propietario» (Piera Miquel, 2009a, nota 16, pp. 93-117).

27 Excepto en 1721-1740 en que se igualan con los militares.

28 Probablemente como consecuencia, en este segmento temporal, de la escasez de documentos. 


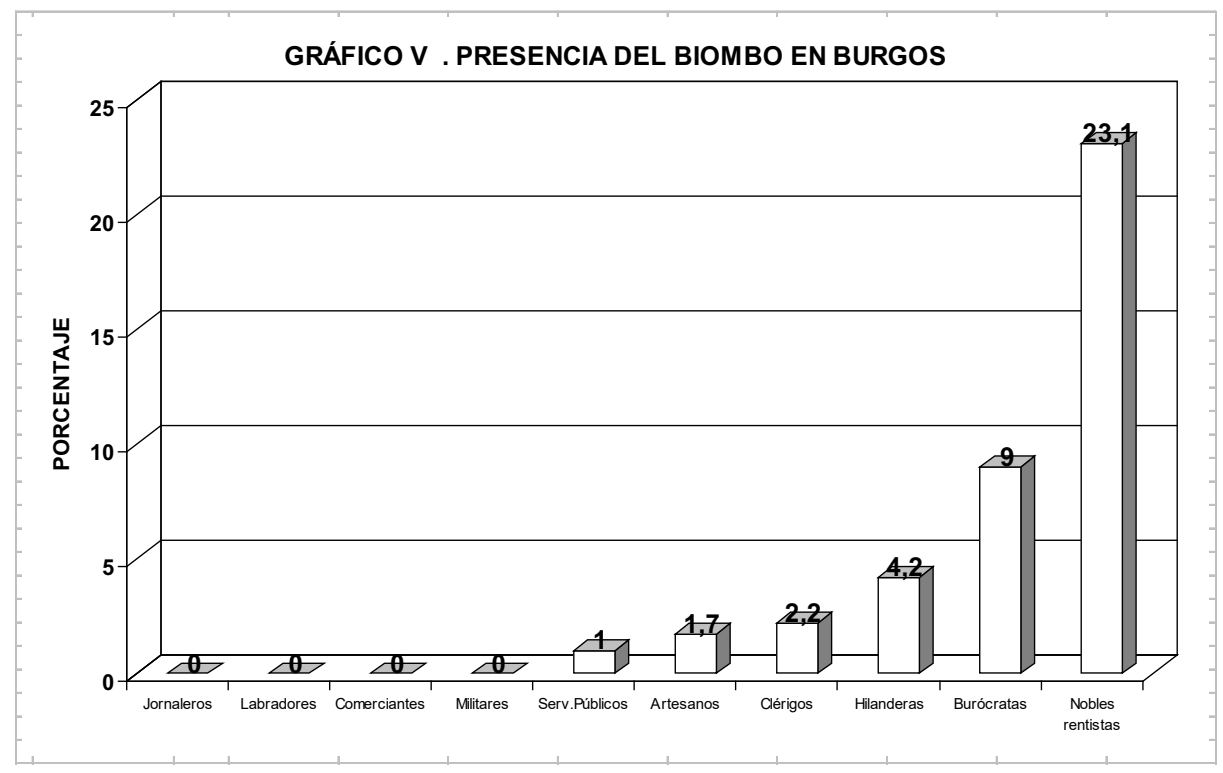

Fuente documental. AHPB. PN y otros Archivos. Múltiples Legajos (1700-1800).

El biombo no estuvo presente en las estancias de jornaleros, labradores y hortelanos, comerciantes y militares en ningún momento -GRáFICO v. Fue muy reducida su asimilación entre los profesionales de los servicios públicos (1 \% de los hogares), los artesanos (1.7\%), los clérigos (2.2\%) y las hilanderas (4.2\%) (1). Entre los burócratas aparece de manera muy tímida (9\% de los inventarios). La categoría socio-profesional que copó su implantación fue, como sucede con el tocador, la nobleza rentista de la ciudad, que disfrutó del biombo en el 23,1 \% de las viviendas. Su evolución a lo largo del siglo - CUADRO II - es igualmente significativa. Las hilanderas lo disfrutaron de manera tardía, pero en 1741-1780 entraron con fuerza en su disponibilidad -con un $9.1 \%$ en tales años-. Los eclesiásticos únicamente dispusieron de biombo en 1741-1760, de forma atenuada (8.7\%). Más minoritario, pero igualmente tardío, fue lo ocurrido en los hogares de artesanos, con un $3.4 \%$ de presencia en 1741-1780 y un $2.4 \%$ en 1781-1800. El devenir del biombo en los hogares de los burócratas es, como con los nobles rentistas, paradigmático. Los burócratas iniciaron el XVIII con una presencia de biombos escasa ( $2.7 \%$ en 1700 $1720)$, un $3.4 \%$ en 1721-1740 y ninguno en 1741-1760. Empero, después, dieron un salvo cualitativo y cuantitativo denodado hasta alcanzar el $25 \%$ de presencia en 1761-1780, si bien descienden al $15.4 \%$ en 1781-1800. En las viviendas de los nobles rentistas, la diacronía del biombo fue más espectacular, aunque marcada por cierta irregularidad. Entran en el siglo con el $16.7 \%$, se eleva hasta el $29.2 \%$ en $1721-1740$, sufre un severo retroceso en $1741-1760$ (23.1\%) y $1761-1780$ (12.5\%), pero llega a su máximo esplendor en $1781-1800$ con el $35.7 \%$ de presencia. El efecto emulación parece aceptable. 


\begin{tabular}{|c|c|c|c|c|c|c|c|}
\hline CUADRO II & \multicolumn{6}{|c|}{ Evolución de la presencia de biombos en los hogares de Burgos (\%) } \\
\hline & $1700-1720$ & $1721-1740$ & $1741-1760$ & $1761-1780$ & $1781-1800$ & Total \\
\hline Hilanderas & 0 & 0 & 9.1 & 9.1 & 0 & 4.2 \\
\hline Jormaleros & 0 & 0 & 0 & 0 & 0 & 0 \\
\hline Labradores & 0 & 0 & 0 & 0 & 0 & 0 \\
\hline Artesanos & 0 & 0 & 3.4 & 3.4 & 2.4 & 1.7 \\
\hline Comerciantes & 0 & 0 & 0 & 0 & 0 & 0 \\
\hline Burócratas & 2.7 & 3.4 & 0 & 25 & 15.4 & 9 \\
\hline Serv. Públicos & 0 & 0 & 0 & 4 & 0 & 1 \\
\hline Nobles rentistas & 16.7 & 29.2 & 23.1 & 12.5 & 35.7 & 23.1 \\
\hline Clérigos & 0 & 0 & 8.7 & 0 & 0 & 2.2 \\
\hline Militares & 0 & 0 & 0 & 0 & 0 & 0 \\
\hline
\end{tabular}

Fuente documental: AHPB y otros Archivos. Múltiples Legajos (924 documentos).

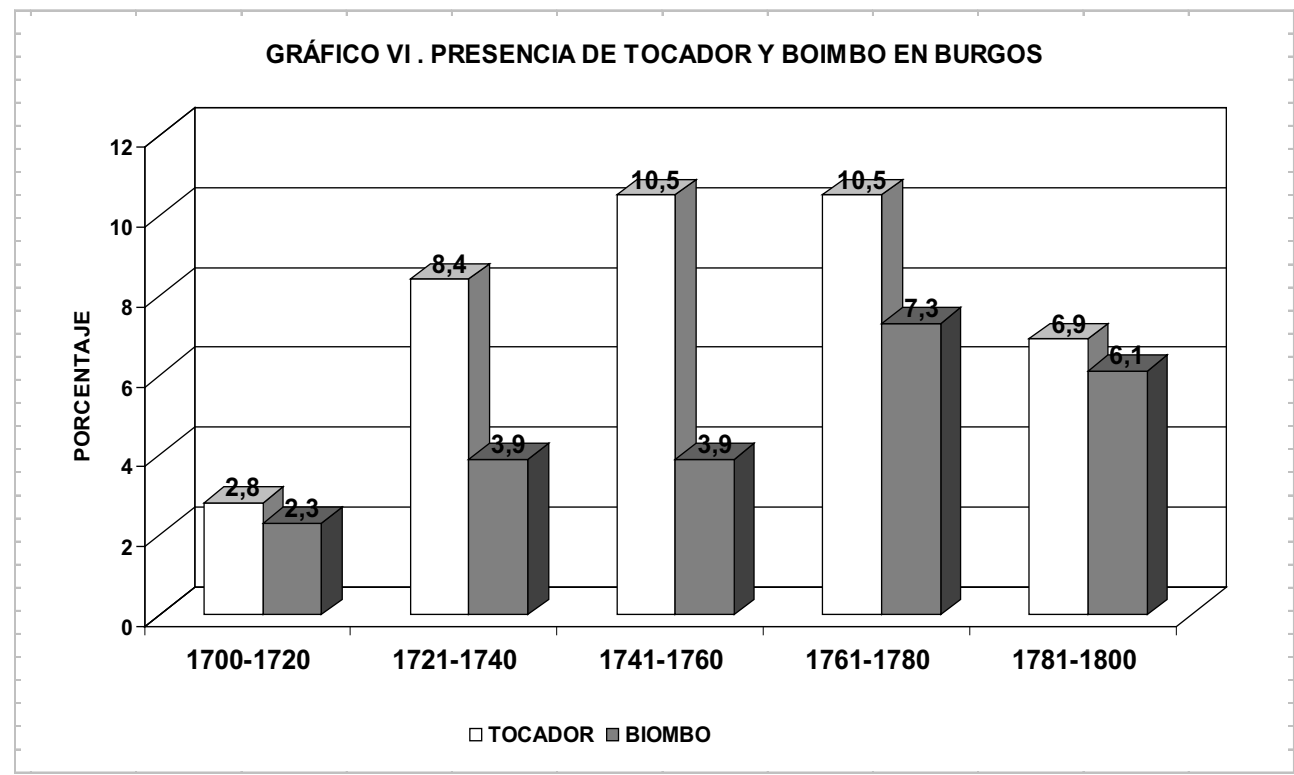

Fuente documental. AHPB. PN y otros Archivos. Múltiples Legajos (1700-1800).

El análisis de la presencia en los hogares del tocador y el biombo, abordada desde otras perspectivas, complementa lo averiguado en el perfil socio-profesional. Resulta evidente que el tocador -GRÁFICO VI- era, básicamente, un mueble para hogares de extracción nobiliar, con anecdóticas apariciones del estado llano y de lo clerical. Es esencial señalar que fueron nobles, sin ninguna interferencia, quienes disfrutaron de tocador en la ciudad de Burgos en 1700-1720-su presencia se detecta en el $10.2 \%$ de los hogares de ese estamento privilegiado. En el segmento temporal 1721-1740 asoman tímidamente un hogar pechero -con un $0.8 \%$ de presencia en tales hogares ${ }^{29}$-, si bien los de extracción nobiliar alcanzaron el entorno del $25 \%$. Ese índice lo van a mantener durante prácticamente gran parte de la centuria,

$291.2 \%$ en $1741-1760$. 
con el $23.1 \%$ en $1741-1760$ y el $25.3 \%$ en $1761-1780$. En 1781-1800 decayó hasta el $17.8 \%$. El estamento clerical únicamente es visible en $1761-1780$ con el $6.7 \%$ de los hogares recopilados.

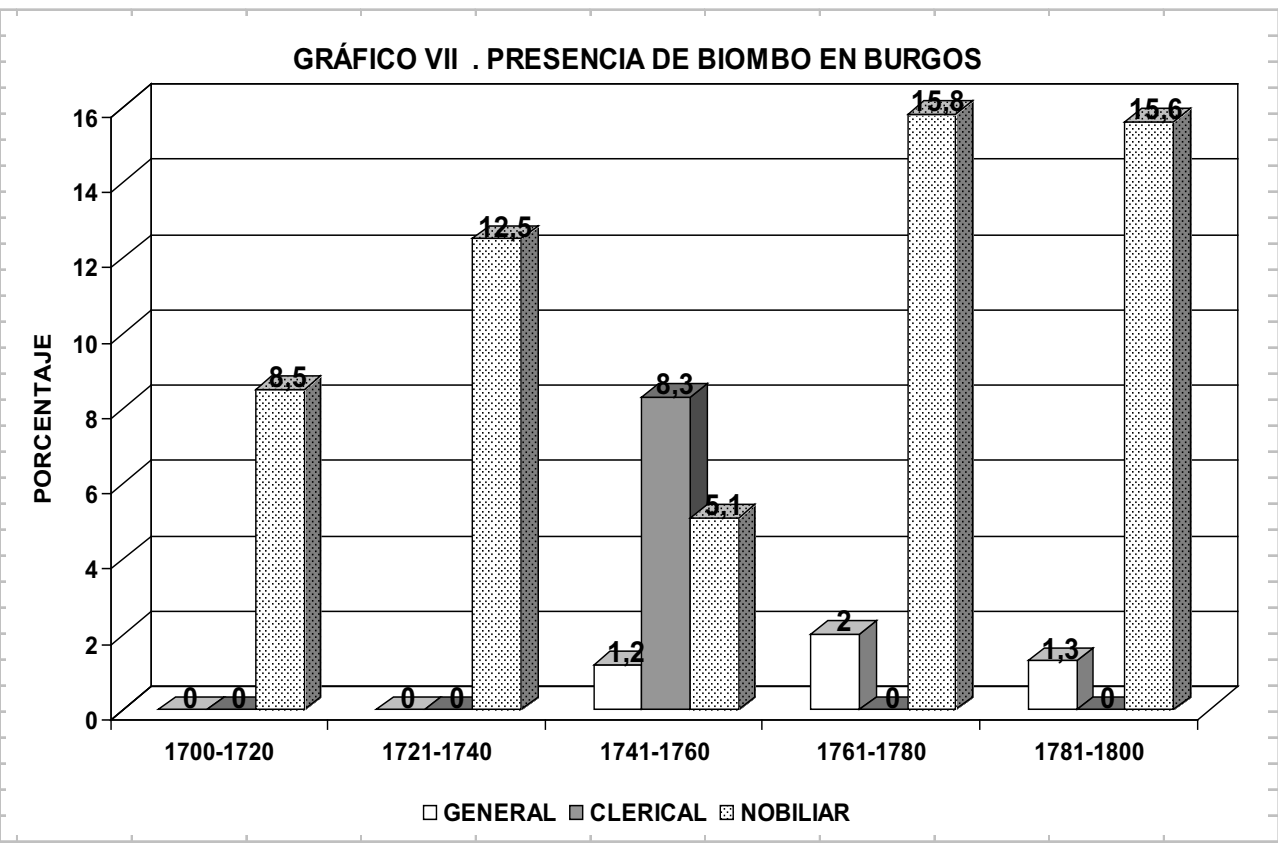

Fuente documental. AHPB. PN y otros Archivos. Múltiples Legajos (1700-1800)

El biombo es igualmente un elemento doméstico esencialmente nobiliar -GRÁFICO VII. En gran parte, se reiteran los asertos del párrafo anterior. Eran hogares nobles los únicos propietarios de biombos en 1700-1720. Se disparan hasta alrededor del $12-15 \%$ en el resto del siglo (1741-1760). El biombo llega a las casas pecheras tarde y cuando lo hace es en porcentajes muy reducidos $-1.2 \%$ en $1741-1760,2 \%$ en $1761-1780$ y $1.3 \%$ en $1781-1800$. Los eclesiásticos solo concurren al disfrute del biombo en el estadio temporal $1741-1760$ con un sorprendente $8.3 \%$ de los inventarios. 


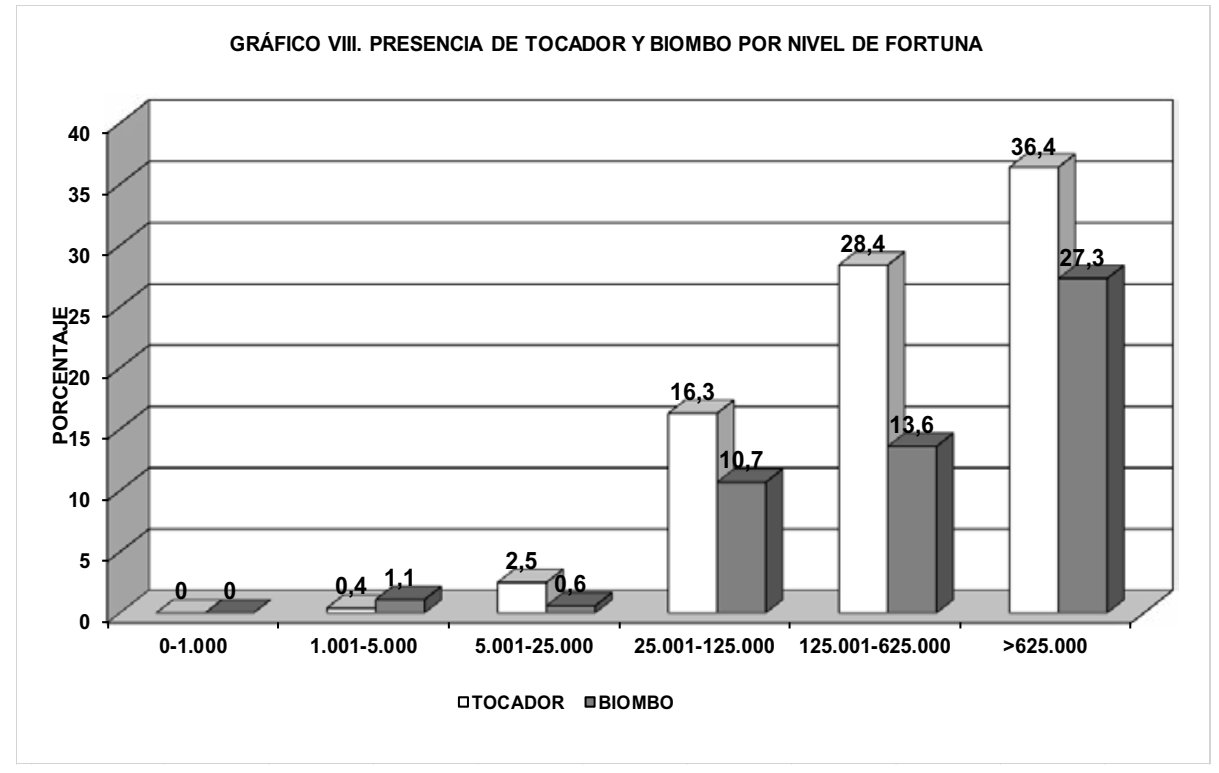

Fuente documental. AHPB. PN y otros Archivos. Múltiples Legajos (1700-1800).

El análisis de la presencia del tocador y el biombo transita, además de por lo socio-profesional y lo estamental, por la consideración de los niveles de fortuna de sus propietarios. A todas luces, eran, sobre todo, hogares del estado noble, rentistas, militares y burócratas, que acumulaban patrimonios libres de gran envergadura -GRÁFICO VIII. El tocador y el biombo no eran muebles aptos para niveles de fortuna raquíticos. En los hogares con un patrimonio inferior a 1.001 reales de vellón no hay ninguno. En los hogares con un nivel de fortuna entre 1.001 y 25.000 reales apenas unos pocos. Más allá de los 25.000 reales, los hogares se dotaban, por la calidad de su capacidad adquisitiva y por la necesidad de maniobrar en siempre exigente, y perturbadora, cultura de las apariencias, de ambos enseres con índices muy significativos. De hecho, la progresión es manifiesta. La aclimatación del tocador alcanza el $16.3 \%$ en los hogares con patrimonios libres entre 25.001 y 125.000 reales, hasta el $28.4 \%$ en los poseedores de niveles de fortuna de 125.001 a 625.000 reales y el $36.4 \%$ entre los más acaudalados -más de 625.000 reales. El biombo repite, aunque con índices de menor calado, lo dicho en el párrafo anterior.

\section{VALORACIÓN ECONÓMICA DEL TOCADOR Y DEL BIOMBO}

A través del GRÁFICO IX se deja constancia del promedio de la tasación económica de los tocadores y biombos aprehendidos en los inventarios de bienes. En la práctica, y relacionado con lo dicho anteriormente, nos topamos, por lo tocante al tocador, en primera instancia, con tres tendencias esenciales. 


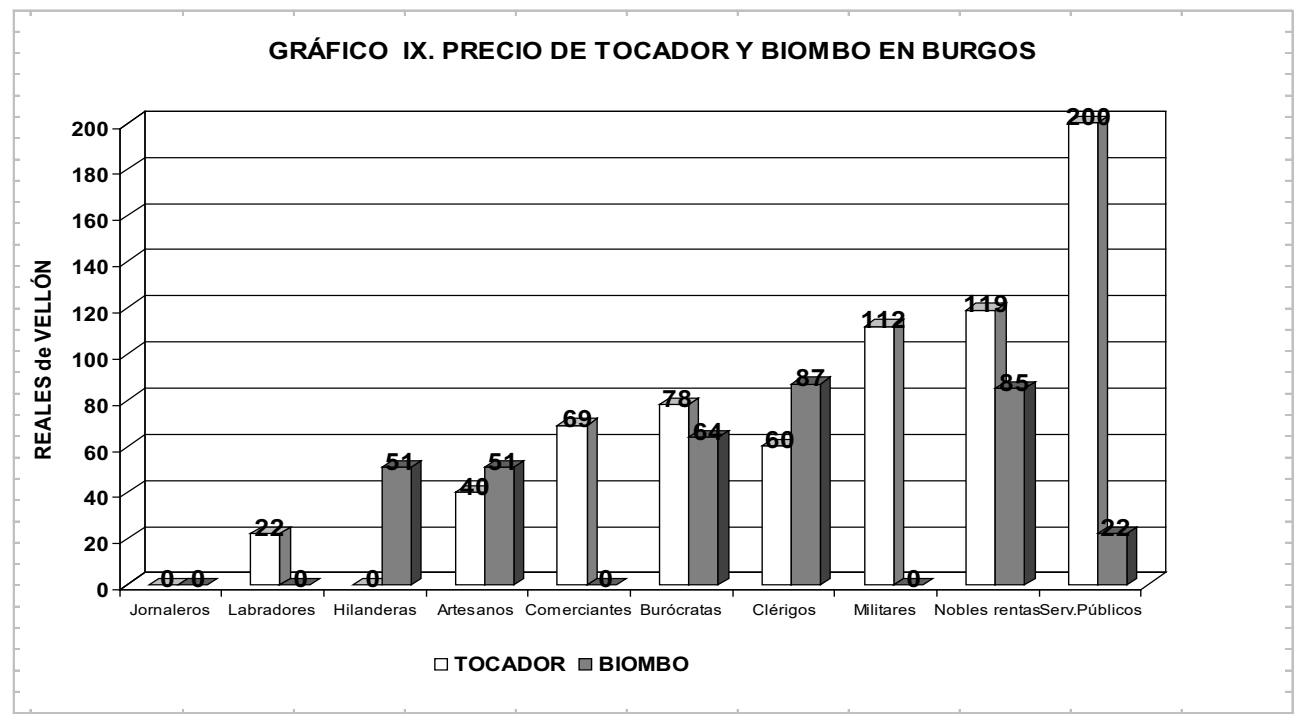

Fuente documental. AHPB. PN y otros Archivos. Múltiples Legajos (1700-1800).

En primer lugar, la de quienes disponían de tocador y/o biombo en sus estancias, pero estos eran de una calidad escasa y un precio reducido. En este segmento se alinean los labradores ${ }^{30}$, las hilanderas y los artesanos ${ }^{31}$. Los promedios de dichos muebles estaban siempre por debajo de los 100 reales/mueble, con promedios entre 22 y 51 reales -CUADRO III y CUADRO IV. En segunda instancia, las categorías socio-profesionales que, en un escalón intermedio-¿clases medias?- disfrutaron de un tocador o un biombo no demasiado paupérrimo pero tampoco de sublime empaque. En este sentido, los comerciantes, los burócratas y los clérigos, poseyeron dichos muebles con promedios entre 69 y 87 reales. No obstante, es indicativo que los burócratas dispusieran de tres magnitudes diferentes en la tasación del tocador. El 70.6 \% tenía tocadores de escaso precio, por debajo de los 100 reales -con un promedio de 24 reales. El 23.5 \% disfrutó de un tocador tasado entre 101 y 300 reales -de promedio, 170 reales-y los más afortunados, el $5.9 \%$, con el tocador evaluado entre 301 y 900 reales -de promedio, 360 reales.

${ }^{30}$ Esta denominación genérica agrupa, simultáneamente, a los labradores y los hortelanos.

${ }^{31}$ Maestros y oficiales artesanos. 


\begin{tabular}{|c|c|c|c|c|c|c|c|c|c|}
\hline \multirow[t]{3}{*}{ CUADRO III } & \multicolumn{8}{|c|}{ Tasación del tocador en el hogar burgalés del XVIII } & \\
\hline & & $0-100$ & & & $101-300$ & & \multicolumn{3}{|c|}{$301-900$} \\
\hline & $\mathrm{N}^{\circ}$ & $\%$ & $\mathrm{RV}(1)$ & $\mathrm{N}^{\circ}$ & $\%$ & RV (1) & $\mathrm{N}^{\circ}$ & $\%$ & $\mathrm{RV}(1)$ \\
\hline Labradores & 1 & 100 & 22 & & & & & & \\
\hline Artesanos & 2 & 100 & 40 & & & & & & \\
\hline Comerciantes & 5 & 100 & 69 & & & & & & \\
\hline Burócratas & 12 & 70.6 & 24 & 4 & 23.5 & 170 & 1 & 5.9 & 360 \\
\hline Serv. Públicos & & & & 1 & 100 & 200 & & & \\
\hline Nobles rentistas & 40 & 67.8 & & 14 & 23.7 & 152 & 4 & 6.8 & 437 \\
\hline Clérigos & 1 & 100 & 60 & & & & & & \\
\hline Militares & 1 & 33.3 & 66 & 2 & 66.7 & 270 & & & \\
\hline \multirow[t]{3}{*}{ Total Ciudad } & 62 & 69.7 & 46 & 21 & 23.6 & 162 & 5 & 5.6 & 422 \\
\hline & & $>900$ & & \multicolumn{3}{|c|}{ Total Ciudad } & & & \\
\hline & $\mathrm{N}^{\circ}$ & $\%$ & $\mathrm{RV}(1)$ & $\mathrm{N}^{\circ}$ & $\%$ & RV (1) & & & \\
\hline Labradores & & & & 1 & 100 & 22 & & & \\
\hline Artesanos & & & & 2 & 100 & 40 & & & \\
\hline Comerciantes & & & & 5 & 100 & 69 & & & \\
\hline Burócratas & & & & 17 & 100 & 78 & & & \\
\hline Serv. Públicos & & & & 1 & 100 & 200 & & & \\
\hline Nobles rentistas & 1 & 1.7 & 1.000 & 59 & 100 & 119 & & & \\
\hline Clérigos & & & & 1 & 100 & 60 & & & \\
\hline Militares & & & & 3 & 100 & 112 & & & \\
\hline Total Ciudad & 1 & 1.1 & 1.000 & 89 & 100 & 105 & & & \\
\hline RV (1): Prom & dio e & reales & de velló & & & & & & \\
\hline
\end{tabular}

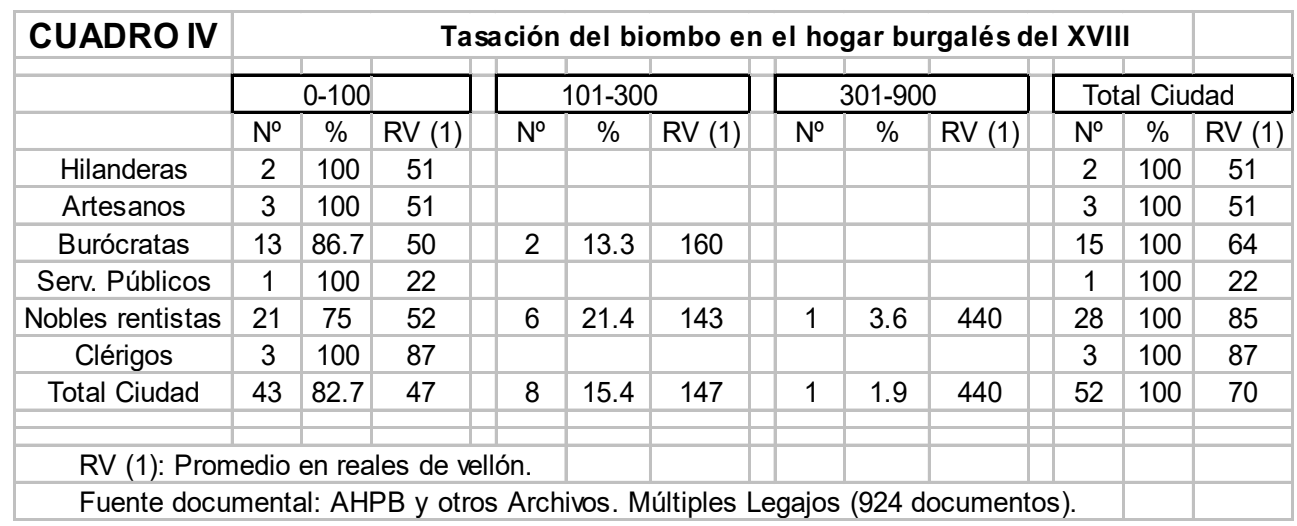

A la postre, en tercer lugar, los militares, los nobles rentistas y los profesionales de los servicios públicos. La consideración del tocador del susodicho boticario Pérez de Limpias genera una distorsión gráfica, consecuencia de su exclusividad documental. El tocador de dicho hogar, tasado en 200 reales, supera, de manera efectista, a los tocadores de los nobles rentistas, que alinean en sus filas tocadores tasados por encima de los 300 reales -cuatro entre 301 y 900 reales $(6.8 \%$ de los casos) y uno en mil reales ( $1.7 \%$ de los tocadores). Descuellan, en efecto, además del ya citado tocador de María Fausta de La Gasca (1.000 reales de 
vellón) $)^{32}$, el «tocador nuevo de moda de Charol encarnado fino con sus Matices y espejo grande, Cajoncillos y Navetas» del también aristócrata Juan Antonio María Enríquez Cisneros ${ }^{33}$, el igualmente citado anteriormente de Juan Manuel Carrillo (400 reales) ${ }^{34}$ o el "tocador de Yndias en butido de diferentes géneros» (400 reales) del igualmente noble rentista Gonzalo Hoces Córdoba ${ }^{35}$. El biombo no alcanza, ni de lejos, la rotundidad del tocador, dado que es uno de los más baratos de los hallados. Los militares detentaban tocadores de calidad mediana -el $66.7 \%$ fueron tasados entre 101 y 300 reales (con un promedio de 270 reales)- o más ordinarios -el $33.3 \%$ era poseedor de un tocador de escaso precio, con un promedio de 66 reales.

\section{LAS MADERAS DEL TOCADOR Y LAS TELAS EN LOS BIOMBOS}

Aunque lamentablemente desconocemos el $71.9 \%$ de las maderas con que estaban fabricados ${ }^{36}$, en el otro afortunado $28.1 \%$ el escribano dejó constancia de cuál era la materia prima de los tocadores inventariados -CUADRO V ${ }^{37}$. La denominación «India»-quizá el palisandro-genera, es obvio, una perturbación documental, pero, a la postre, es aceptable ${ }^{38}$. Las dos maderas más ordinarias de las utilizadas para armar un tocador, el cedro y el nogal, están asociadas, sobre todo, a los comerciantes y a los clérigos, al $100 \%$, respectivamente, y a los burócratas, al $75 \%$. Las maderas más exóticas, tropicales y caras -India, granadillo, ébano, caoba y palo santo-, conforman el tocador en las casas de un $25 \%$ de los burócratas y del $66.7 \%$ en las viviendas de los nobles rentistas. El tocador de cedro era el más asequible, con un promedio de 37 reales, seguido del de nogal (51 reales), del de

${ }^{32}$ AHPB. PN. José Fernández Guilarte. Legajo 7004 (23 de febrero de 1734), folio 220v.

33 AHPB. PN. Santiago Romo. Legajo 6980 (17 de junio de 1734), folio 75r.

${ }^{34}$ AHPB. PN. Jacinto del Río. Legajo 7054/3 (3 de noviembre de 1756), folio 368.

${ }^{35}$ AHPB. PN. Jacinto del Río. Legajo 7051/2 (24 de octubre de 1738), folio 223r.

36 Sobre qué maderas se utilizaban en los muebles en el siglo XVIII véanse, entre otras opciones, Ramos Palencia, 2010, nota 15, pp. 137 y 144-145; Franco, 2007; Echalecu, 1957; López Castán, 2004, nota 20, p. 132 y Ojeda San Miguel, 1988.

37 Las apreciaciones que se efectúan en este apartado están sujetas, evidentemente, a la consideración de los tocadores de cuya madera tenemos constancia cierta. Pero no hemos de olvidar que solo accedemos, como se ha señalado, al $28.1 \%$ de las piezas, lo cual genera una significativa incertidumbre sobre el resto, y se pueden hacer análisis poco creíbles.

${ }^{38}$ En el inventario post-mortem de Gabriel Díaz Salvador, mayordomo del Cabildo Catedral en 1701-1708, se anotó "Un Tocador de madera de la Yndia sin mesa» (132 reales). AHPB. PN. José Fernández Guilarte. Legajo 6899 (6 de agosto de 1708), folio 299r. En el del susodicho Gonzalo Hoces Córdoba, regidor perpetuo en el Concejo, el escribano dejó constancia de la presencia de «Un Tocador de Yndias en butido de diferentes géneros» (400 reales). AHPB. PN. Jacinto del Río. Legajo 7051/2 (24 de octubre de 1738), folio 223r. 
palo santo y caoba (90 reales), del de granadillo o el de caoba ( 150 reales), del de ébano (167 reales) y, en último término, el de "Yndia», de promedio 266 reales. El contraste entre las categorías socio-profesionales proto-burguesas, comerciantes y burócratas, con el tocador en cedro y nogal, y las categorías, y extracciones estamentales, privilegiadas -nobles rentistas, clérigos y militares, poseedores de tocadores fabricados en granadillo, ébano, caoba o palo santo, confirma un diagnóstico socio-económico esencial. A mayor altura en la pirámide social, mejores maderas en el mobiliario.

\begin{tabular}{|c|c|c|c|c|c|c|c|c|c|c|c|c|}
\hline \multirow[t]{3}{*}{ CUADRO V } & \multicolumn{12}{|c|}{ Maderas del tocador en los interiores domésticos de Burgos } \\
\hline & \multicolumn{3}{|c|}{ CEDRO } & \multicolumn{3}{|c|}{ NOGAL } & \multicolumn{3}{|c|}{ INDIA } & \multicolumn{3}{|c|}{ GRANADILLO } \\
\hline & $\mathrm{N}^{0}$ & $\%$ & $\mathrm{RV}(1)$ & $\mathrm{N}^{\circ}$ & $\%$ & $\mathrm{RV}(1)$ & $\mathrm{N}^{0}$ & $\%$ & RV (1) & $\mathrm{N}^{0}$ & $\%$ & RV (1) \\
\hline Comerciantes & 1 & 33.3 & 55 & 2 & 66.7 & 70 & & & & & & \\
\hline Burócratas & 2 & 50 & 29 & 1 & 25 & 50 & 1 & 25 & 132 & & & \\
\hline Nobles rentistas & & & & 4 & 33.3 & 50 & 1 & 8.3 & 400 & 2 & 16.7 & 150 \\
\hline Clérigos & & & & 1 & 100 & 60 & & & & & & \\
\hline \multirow{4}{*}{$\begin{array}{c}\text { Militares } \\
\text { Total Ciudad }\end{array}$} & & & & & & & & & & & & \\
\hline & 3 & 14.3 & 37 & 8 & 38.1 & 51 & 2 & 9.5 & 266 & 2 & 9.5 & 150 \\
\hline & \multicolumn{3}{|c|}{ ÉBANO } & \multicolumn{3}{|c|}{ CAOBA } & \multicolumn{3}{|c|}{ PALO SANTO } & \multicolumn{3}{|c|}{ TOTAL CIUDAD } \\
\hline & $\mathrm{N}^{\circ}$ & $\%$ & $\mathrm{RV}(1)$ & $\mathrm{N}^{\circ}$ & $\%$ & $R \vee(1)$ & $\mathrm{N}^{\circ}$ & $\%$ & $\mathrm{RV}(1)$ & $\mathrm{N}^{\circ}$ & $\%$ & $\mathrm{RV}(1)$ \\
\hline Comerciantes & & & & & & & & & & 3 & 100 & \\
\hline Burócratas & & & & & & & & & & 4 & 100 & \\
\hline Nobles rentistas & 3 & 25.1 & 167 & 1 & 8.3 & 150 & 1 & 8.3 & 60 & 12 & 100 & \\
\hline Clérigos & & & & & & & & & & 1 & 100 & 60 \\
\hline Militares & & & & & & & 1 & 100 & 120 & 1 & 100 & 120 \\
\hline Total Ciudad & 3 & 14.3 & 167 & 1 & 4.8 & 150 & 2 & 9.5 & 90 & 21 & 100 & 106 \\
\hline
\end{tabular}

En lo tocante a los biombos, tres son los aspectos a destacar en cuanto a su factura. En primer lugar, el número de los bastidores ${ }^{39}$, "órdenes»" ${ }^{40}$, «telas»",

39 Véase, por ejemplo, el «Biombo de dos Varas de altto y de ocho Bastidores, pinttado por ambas Caras» (60 reales) de Casilda Gallo. AHPB. PN. Francisco Villafranca. Legajo 7096/1 (17 de enero de 1764), folio $35 \mathrm{r}$.

40 Véase, por ejemplo, el "Biombo de dos bara y media de altto de ocho órdenes» (120 reales) de Juan Francisco Santamaría. AHPB. PN. Juan Francisco García de la Pinilla. Legajo 6985/2 (15 de octubre de 1727), folio 300r.

41 Véase, por ejemplo, el «Biombo de ocho Telas de dos Varas y media de largo» (120 reales) que Francisco Antonio Gallo Haro, marqués de Fuentepelayo, tenía dispuesto en el "Cuarto principal» de su vivienda. AHPB. PN. Diego Fernández Cormenzana. Legajo 7077 (28 de mayo de 1740), folio $456 r$. 
«piezas» ${ }^{42}$, «paños» ${ }^{43}$ o "tablas» ${ }^{44}$ de los que estaban compuestos. En segundo término, los tejidos que los conformaban y, a la postre, las representaciones que aparecen en sus piezas. La inmensa mayoría de los biombos tenían ocho bastidores (75.2 \%), pero también se detectan algunos con tres, cinco, siete y nueve bastidores (3.1\%, respectivamente) y otros con cuatro y seis bastidores (1) $(6.2 \%$, respectivamente).

Las telas de los bastidores eran, al $100 \%$, de angeo para los biombos de los artesanos, y del $88.9 \%$ para los burócratas -también aparece un $11.1 \%$ en arpillera y angeo, simultáneamente. Eran los nobles rentistas quienes, como en todo, disfrutaban de una mayor variedad de tejidos. El $50 \%$ de los biombos eran de angeo, el $16.7 \%$ de damasco verde y de lienzo, respectivamente, y con una presencia más escasa la seda fina y la beatilla, con un $8.3 \%$ cada una de ellas.

No son muchas las descripciones de los biombos hechas por los escribanos en que se nos advierta de qué escenas contenían sus bastidores. Descuellan, por ejemplo, el "Biombo de seis Bastidores y dos y una quarta varas de alto, Forrado en Angeo y pintado de Barios Colores» (24 reales) aparecido en casa del escribano Diego Fernández Cormenzana ${ }^{45}$. También el "Biombo de Ocho Bastidores de Angeo, pintado de Montería» (66 reales), anotado en el "Quarto Segundo» de la casa del Administrador General de las Rentas Reales Félix Sánchez de Valencia ${ }^{46}$. En la vivienda de Casilda Gallo nos topamos con «Un Beonbo de dos Varas de altto y Ocho Bastidores, pinttado por ambas caras» (60 reales) ${ }^{47}$. "Un Biombo de Lienzo pintado de Arboledas» se descubre en el hogar del aristócrata Gonzalo del Río Zorrilla ${ }^{48}$ y, en último termino, el "Biombo de Ocho Bastidores de Lienzo encerado y Varias pinturas» de Jacinto Cilleruelo ${ }^{49}$.

42 Véase, por ejemplo, el «Biombo pequeño desarmado de Ocho piezas de Vara y quarta de Caida» (30 reales) de Lope de Hoces y Josefa de Salamanca. AHPB. PN. Juan Antonio Fernández Guilarte. Legajo 7008 (29 de diciembre de 1741), folio 669v.

${ }^{43}$ Véase, por ejemplo, los «dos Biombos de ocho paños» (160 reales) del regidor perpetuo Felipe Antonio de Salamanca y Moreda. AHPN. PN. José Guadilla. Legajo 7132 (8 de julio de 1782), folio 692r.

${ }^{44}$ Véase, por ejemplo, el «biombo con siette tablas debidido en dos Pedazos» (100 reales) de Juan Escalada. AHPB. PN. Lázaro Santamaría. Legajo 6871 (22 de noviembre de 1718), folio $547 r$.

45 AHPB. PN. Miguel Varona. Legajo 7208 (19 de enero de 1768), folio 273v.

46 AHPB. PN. José Guadilla. Legajo 7131 (27 de febrero de 1778), folio 744r.

47 AHPN. PN. Francisco Villafranca. Legajo 7096/1 (17 de enero de 1764), folio 35r.

48 AHPB. PN. Diego Fernández Cormenzana. Legajo 7075 (27 de noviembre de 1736), folio $365 r$.

49 AHPB. PN. Rafael Pérez Romo. Legajo 7244 (1 de junio de 1781), folio 60r. 


\section{UBICACIÓN DEL TOCADOR YEL BIOMBO EN LOS INTERIORES DOMÉSTICOS}

Enfatiza Piera Miquel que «es necesario fijarse en las propuestas del país vecino para comprender el cambio de ubicación del mueble tocador dentro de la vivienda. Si los ejemplares franceses se habían colocado hasta ahora en el dormitorio, los nuevos planos arquitectónicos los sitúan en una estancia específica para su uso, denominada toilette, y que nace como complemento del dormitorio y formando parte de los espacios femeninos junto al boudoir» (Piera Miquel, 2009a, nota 16, p. 105; Eleb-Vidal y Debarre-Blanchard, 1989). En el Burgos del XVIII, la ubicación del tocador y del biombo -CUADRO VI- se detecta, cuando el escribano pormenoriza las estancias, en una múltiple variedad de habitaciones, si bien su localización es sintomática de cada categoría socio-profesional. Los profesionales de los servicios públicos y los militares radicaban el tocador, al $100 \%$, en el "Quartto Principal». Eran tocadores de modesta factura -entre 100 y 200 reales- pero localizados en las cercanías del lecho nocturno principal. Los comerciantes, más modestos, los relegaban a estancias secundarias ${ }^{50}$ o reductos domésticos más recónditos ${ }^{51}$. Los promedios de tasación, entre 70 y 80 reales, delimitan tocadores de calidad mediocre. Los burócratas por estrategias de colocación del tocador híbridas. Un $42.8 \%$ de sus tocadores se ubicaron, por una parte, en el «Quartto Prinzipal» -con un promedio, 235 reales, muy elevado, característico de tocadores de notable calidad- $y$, por otra, en las estancias más modestas -con otro $42.8 \%$ en estancias secundarias- 67 reales de promedio -y reductos más escondidos -8 reales de promedio. Los nobles rentistas desplegaban el tocador un poco por todas partes, si bien la mayoría, el $58.4 \%$ estaban ubicados en las estancias secundarias -91 reales de promedio. En el "Quartto Tocador» el $16.7 \%$ -125 reales de promedio. En el "Quartto Prinzipal» y en los reductos domésticos se iguala el porcentaje de ubicación, pero sus precios los diferencian de manera categórica. En la primera opción, el promedio del tocador es de 140 reales y en la segunda de 24 reales. En términos generales, por tanto -CUADRO VI-, el tocador se encontraba localizado en estancias de segundo orden (50\%) -86 reales de promedio-, en los cuartos principales (19.5\%) -190 reales de promedio-, cuartos pequeños, oscuros o desvanes (13.9\%) -42 reales de promedio-, en el estrado (11.1\%) -125 reales de promedio- o en el "Quartto Tocador» por antonomasia (5.5\%) -95 reales de promedio. La tasación es indicativa de su calidad e importancia.

La ubicación del biombo para la que disponemos de información privilegió, también, las estancias secundarias $-61.9 \%$, con 69 reales de promedio- sobre el «Quartto principal» $-28.6 \%$, con 61 reales de promedio en la tasación. El «Quartto

${ }^{50}$ Entre las estancias secundarias (QUARTOS ॥) descuellan el "Quartto Salón», el "Quartto Jardín», el "Quartto Gabinette», el «Quartto de Vidrieras» o el «Quartto Segundo».

${ }^{51}$ Bajo la denominación reducto recóndito (QUARTO III) se hallan el «Quartto pequeño», el «Quartto Obscuro» o el «Desban». 
de Estrado» fue la opción menos habitual $-9.5 \%$, con un promedio de 82 reales ${ }^{52}$. El $100 \%$ de sus biombos era colocado en las casas de las hilanderas en el «Quartto Prinzipal». Los burócratas se decantaban más por las estancias secundarias $-66.7 \%$, con un promedio de 60 reales-que por el «Quartto Prinzipal»-35.3\%, si bien el promedio es mucho menor, 36 reales. Los nobles rentistas, como con el tocador, los ubicaban en múltiples estancias, si bien las estancias secundarias eran las más usuales -63.6\%-frente al «Quartto Prinzipal» o el estrado, con un $18.2 \%$, respectivamente.

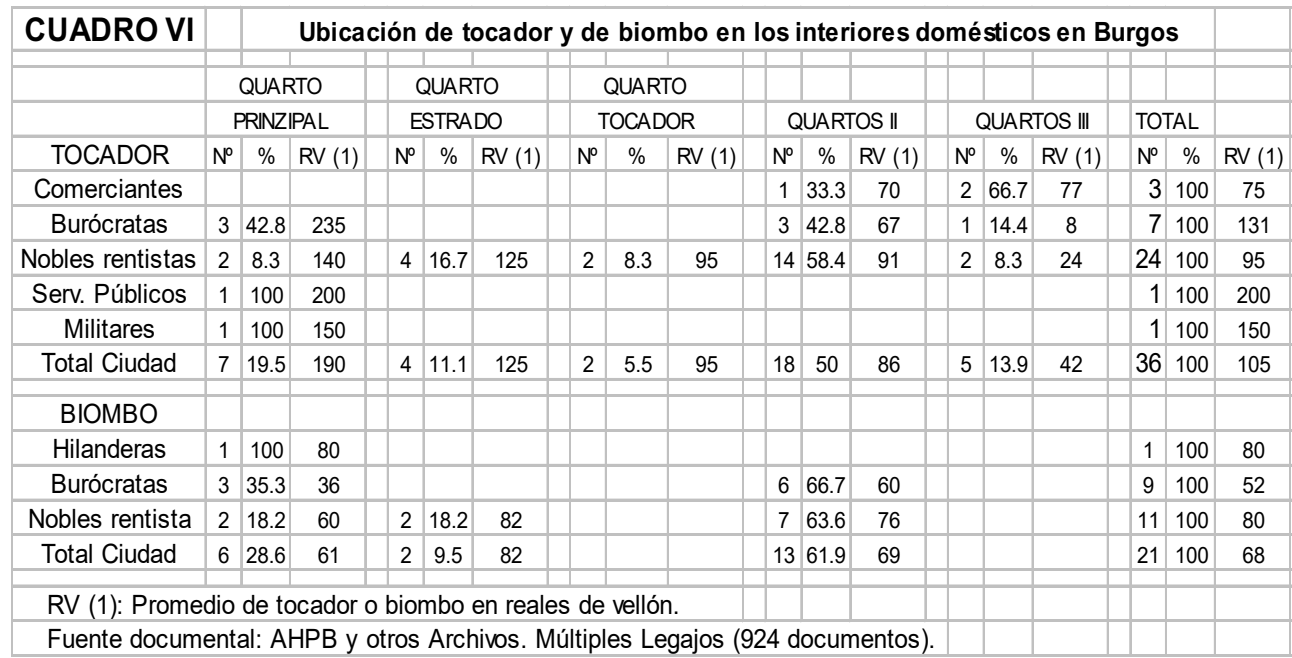

\section{CUANTIFICACIÓN DEL NÚMERO DE TOCADORES Y BIOMBOS}

Lo habitual -GRÁFICO VII- era disponer de un tocador -supone el $74.6 \%$ de las viviendas en general y su presencia fluctúa levemente a lo largo del siglo. Dos tocadores por casa, simultáneamente, se computan en el $18.3 \%$ de los documentos, con una similar apreciación en lo tocante a su devenir temporal. Más extraño es el disfrute de tres tocadores al mismo tiempo, circunstancia que detectamos en un $7.1 \%$. Su presencia fue bastante diferencial según el segmento temporal, con un $16.7 \%$ en $1700-1720$, entre el 5 y $6 \%$ en 1721 y 1780 y el $11.1 \%$ en $1781-1800$. Un biombo únicamente también es la opción preponderante. Ello supone el $78.6 \%$, con notorias fluctuaciones a lo largo de la centuria. El $21.4 \%$ de los hogares disponía de dos biombos, opción sometida también a notorios zig-zag en su presencia.

52 En Nueva España, sin embargo, Pichardo Hernández, indica que «la mayoría se las veces se encuentra en la sala del estrado de una casa, donde se reciben las visitas...». Pichardo Hernández, 2009, nota 34, p. 30; Baena Zapatero, 2007, nota 35, pp. 441-449. 


\begin{tabular}{|c|c|c|c|c|c|c|c|c|c|c|c|c|}
\hline \multirow{3}{*}{$\begin{array}{c}\text { CUADRO VII } \\
\text { TOCADOR }\end{array}$} & & \multicolumn{11}{|c|}{ Número de tocadores y biombos en los hogares burgaleses } \\
\hline & \multicolumn{2}{|c|}{$1700-1720$} & \multicolumn{2}{|c|}{$1721-1740$} & \multicolumn{2}{|c|}{$1741-1760$} & \multicolumn{2}{|c|}{$1761-1780$} & \multicolumn{2}{|c|}{$1781-1800$} & \multicolumn{2}{|c|}{ TOTAL } \\
\hline & $\mathrm{N}^{\circ}$ & $\%$ & $\mathrm{~N}^{\circ}$ & $\%$ & $\mathrm{~N}^{\circ}$ & $\%$ & $\mathrm{~N}^{\circ}$ & $\%$ & $\mathrm{~N}^{\circ}$ & $\%$ & $\mathrm{~N}^{\circ}$ & $\%$ \\
\hline UNO & 5 & 83.3 & 12 & 70.6 & 14 & 73.7 & 15 & 75 & 7 & 77.8 & 53 & 74.6 \\
\hline DOS & & & 4 & 23.5 & 4 & 21.1 & 4 & 20 & 1 & 11.1 & 13 & 18.3 \\
\hline TRES & 1 & 16.7 & 1 & 5.9 & 4 & 5.2 & 1 & 5 & 1 & 11.1 & 5 & 7.1 \\
\hline Total & 6 & 100 & 17 & 100 & 19 & 100 & 20 & 100 & 9 & 100 & 71 & 100 \\
\hline \multicolumn{13}{|l|}{ BIOMBO } \\
\hline UNO & 3 & 60 & 8 & 100 & 4 & 57.1 & 13 & 92.8 & 5 & 62.5 & 33 & 78.6 \\
\hline DOS & 2 & 40 & & & 3 & 42.9 & 1 & 7.2 & 3 & 37.5 & 9 & 21.4 \\
\hline Total & 5 & 100 & 8 & 100 & 7 & 100 & 14 & 100 & 8 & 100 & 42 & 100 \\
\hline
\end{tabular}

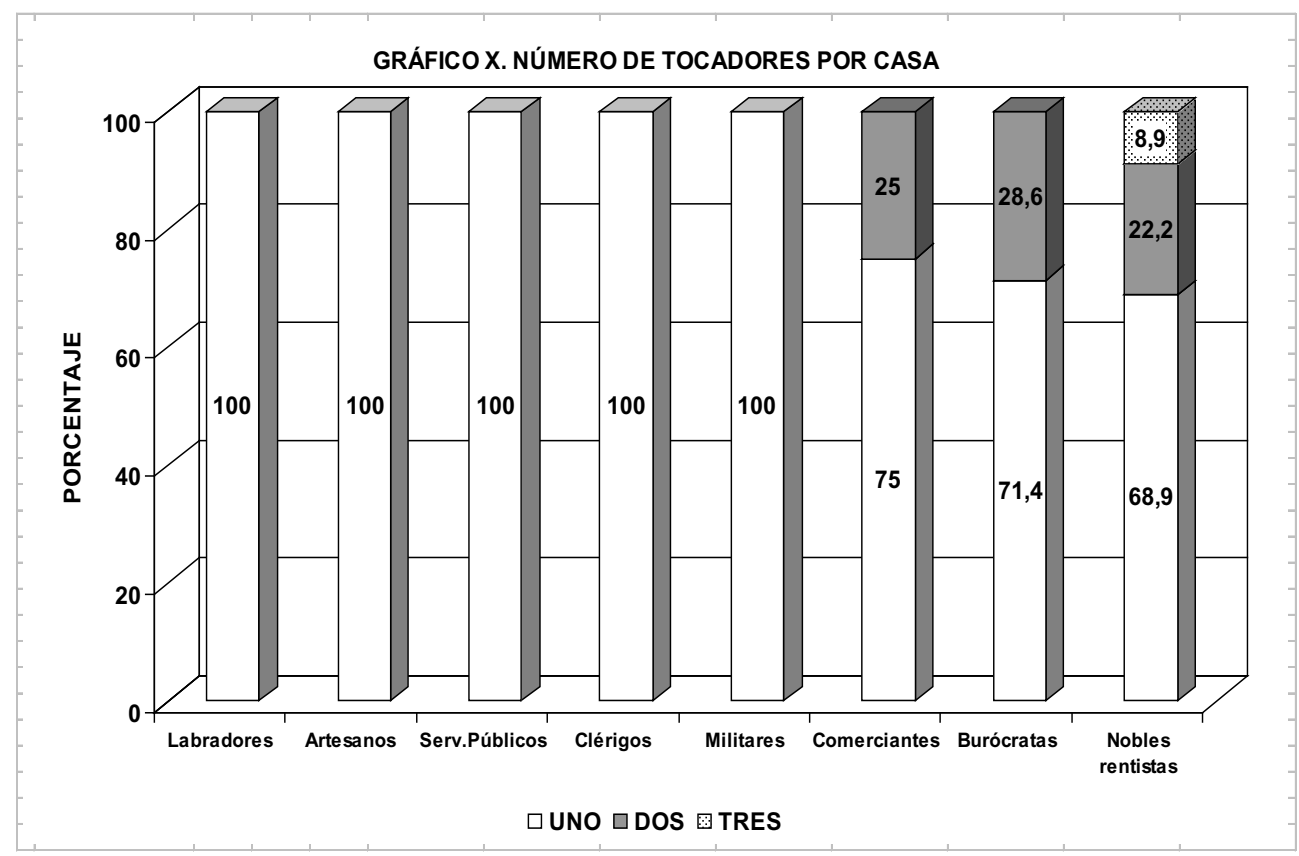

Fuente documental. AHPB. PN y otros Archivos. Múltiples Legajos (1700-1800)

El número de tocadores de que se disponía en cada categoría socio-profesional -GRÁFICO X- es directamente proporcional a los asertos señalados anteriormente y característico de sus posibilidades económicas. Con un único tocador, al $100 \%$, labradores, artesanos, profesionales de los servicios públicos, clérigos y militares. En las casas de comerciantes predominaba disfrutar de un tocador (75 \%) pero en algunos hogares presumían de dos (25\%). Casi lo mismo ocurre en las viviendas de los burócratas ( $71.4 \%$ / $28.5 \%$, respectivamente). Es en las viviendas de los no- 
bles rentistas donde encontramos en una mayor diversidad, con una presencia de tres tocadores en el $8.9 \%$ de los hogares, un $22.2 \%$ con dos y un $68.9 \%$ con uno. Los aristócratas no solo disponían de un número mayor de estancias sino también de tocadores, en especial en los "aposentos de recepción de amplitud (...) [que] fomentaba el uso de muebles de exquisito gusto estético que permitieran crear apartados» (González Heras, 2014, p. 394).

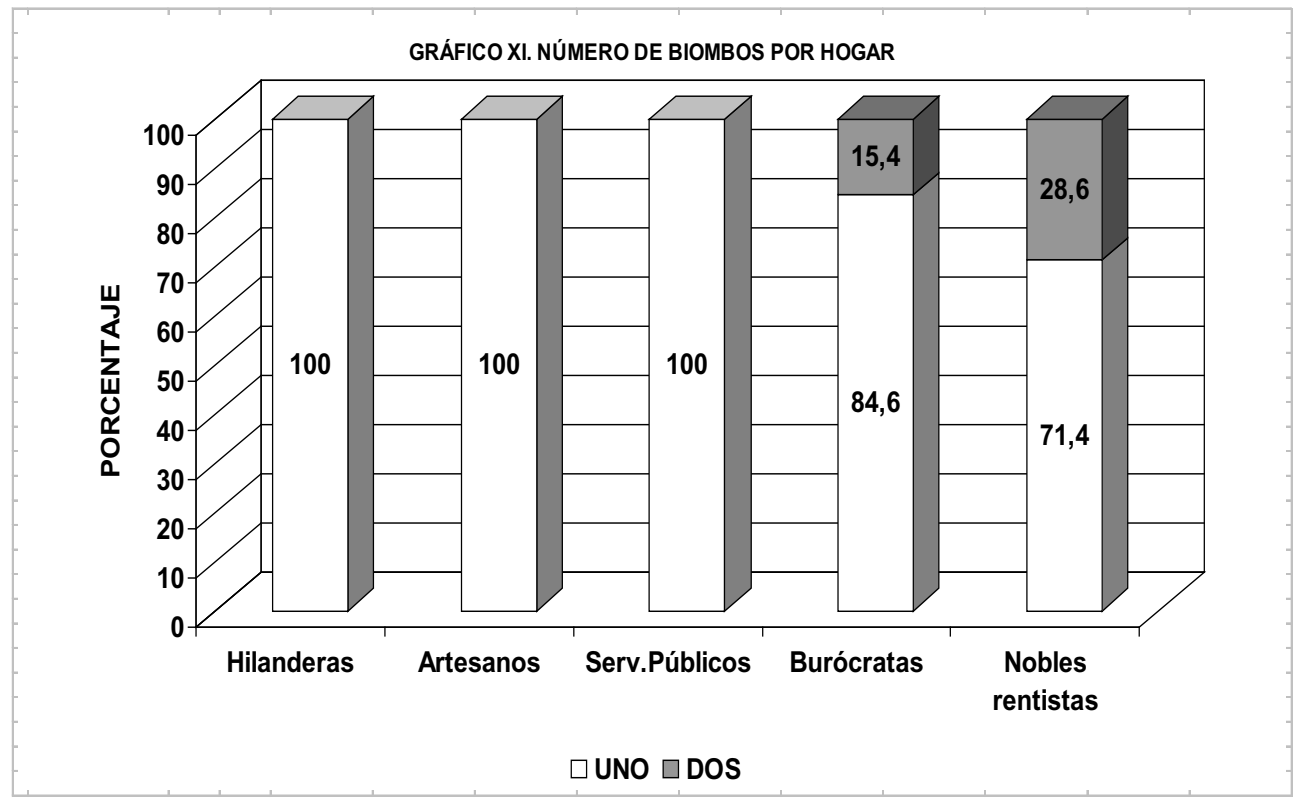

Fuente documental. AHPB. PN y otros Archivos. Múltiples Legajos (1700-1800).

El número de biombos -GRÁFICO XI- es, también, un «escaparate de la estratificación de las desigualdades propias de Antiguo Régimen» (García Fernández, 2017, p. 101). Constituye, evidentemente, una estrategia meditada en el empuño de segmentar, artificiosamente, las estancias, aunque, como señala García Fernández: «El biombo apenas protegía de las miradas extrañas o domésticas» (García Fernández, 2017, p. 101). Aparece un biombo en las casas de hilanderas, artesanos y profesionales de los servicios públicos. Se reparte al $50 \%$, con uno o dos, respectivamente, entre los clérigos. Prima el biombo único ( $84.6 \%$ ) en las viviendas de los burócratas, si bien en el $15.4 \%$ se habían dotado de dos. Documentamos tres biombos simultáneamente en el $28.6 \%$ de las casas de los nobles rentistas -con un solo en el $71.4 \%$. 


\section{7. ¿TOCADOR Y BIOMBO SIMULTÁNEAMENTE?}

Esta circunstancia, es decir, que en una vivienda, en el Burgos del XVIII, se hubieran implantado, al mismo tiempo, tocador y biombo, ocurría solamente en un surtido puñado de hogares, que representan el $1.7 \%$ de los documentos recopilados (924 inventarios). De los 94 inventarios en los que el escribano anotó tocador y/o biombo, únicamente en el $17.1 \%$ sus propietarios disfrutaron de ambos de manera simultánea. Es modélico, a mi entender, el ejemplo recopilado en el inventario post-mortem del administrador de las Rentas Reales José Castilla y Portugal, quien disponía de tres tocadores, instalados dos de ellos en un "Quarto a Cantarranas la menor ${ }^{53}$ y el otro en un "Quarto $q^{e}$ cae a Cantarranas la menor ${ }^{54}$, y dos biombos ubicados en el "Quarto vajo a la esquina de Cantarranas»" ${ }^{55}$ en el "Quarto pral del Jardín $»^{56}$.

Un análisis de las diferentes posibilidades nos vuelve a situar ante la diferencial taxonomía socio-económica -GRÁFICO XII. Hallamos únicamente biombo o biombos en las casas de las hilanderas. Solo tocadores en las viviendas de los profesionales de los servicios públicos, de los comerciantes y de los militares. Entre los labradores, se detectan solo biombos en el $60 \%$ de los documentos implicados y solo tocador en el $40 \%$. Algo similar entre los clérigos -solo biombo en el $66.7 \%$ y solo tocador en el $33.3 \%$. Las categorías socio-profesionales en las que se simultaneaba la presencia de biombo y tocador eran la nobleza rentista y los burócratas. En las viviendas de los burócratas aparecían solo biombos en el $36.4 \%$ de los casos, el $40.9 \%$ solo tocadores y ambos en el importante $22.7 \%$ de los documentos -léase casas. Los nobles rentistas nos ofrecen un panorama parecido, con un $20.4 \%$ de solo biombo, un $59.2 \%$ de solo tocador y un significativo $20.4 \%$ con ambos a la vez.

53 "Un tocador [con] su marco p espejo, pies acarcelados con nuebe Cajoncillos» (50 reales) $\mathrm{y}$ «Un tocador de media vara de largo y más de una tercia de ancho, con embuttidos de Madera blanca, el espejo quevrado» (22 reales). AHPB. PN. José Guadilla. Legajo 7132 (30 octubre de 1786), folio 554 .

54 «Un tocador de a quarta, con sus cajas y pie qe parecen quatro libros, dados de Charol, y dentro sus Cajitas» (130 reales). AHPB. PN. José Guadilla. Legajo 7132 (30 octubre de 1786), folio 568 .

55 "Un Biombo de ocho Lienzos, con varias pintadas» (50 reales). AHPB. PN. José Guadilla. Legajo 7132 (30 octubre de 1786), folio 556r.

56 «Un Biombo vien tratado de ocho paños» (64 reales). AHPB. PN. José Guadilla. Legajo 7132 (30 octubre de 1786), folio 563v. 


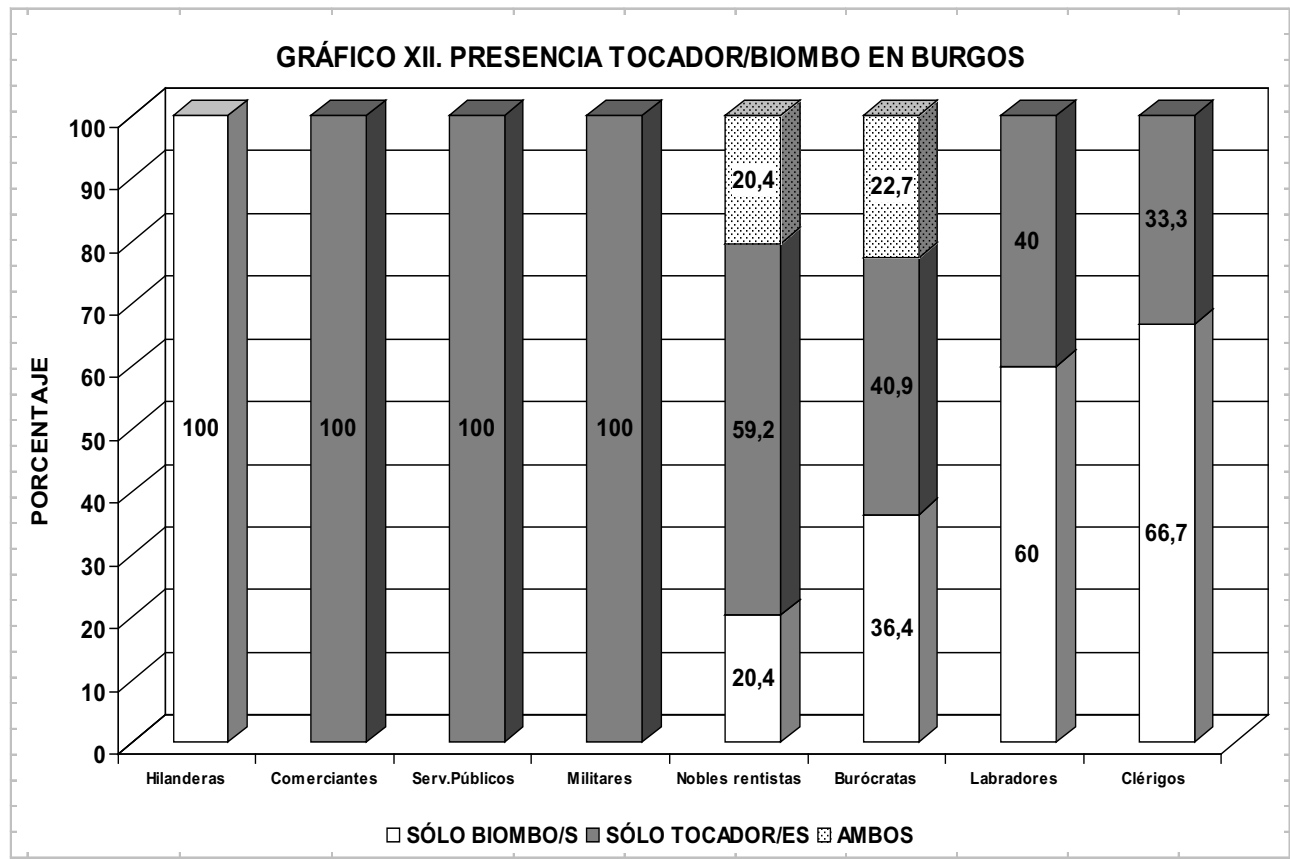

Fuente documental. AHPB. PN y otros Archivos. Múltiples Legajos (1700-1800)

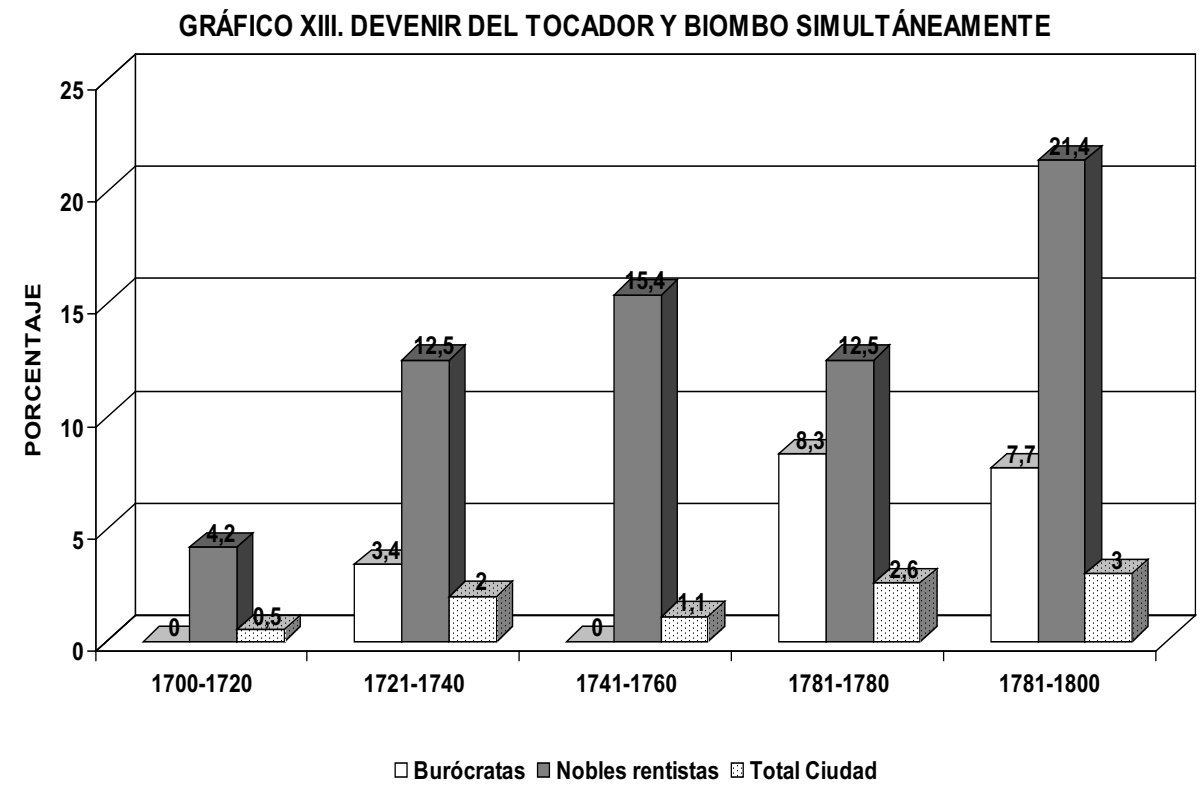

Fuente documental. AHPB. PN y otros Archivos. Múltiples Legajos (1700-1800) 
Esa simultaneidad entre tocador y biombo conoció un devenir cambiante, pero, en general, al alza -GRÁFICO XIII-, tanto desde la perspectiva global como en las dos categorías socio-profesionales implicadas en esa estrategia habitacional. El carácter creciente, salvo ligeros titubeos puntuales, de ese devenir nos advierte, a mi juicio, de un comportamiento doméstico en el que existieron decisiones conscientes para incorporar el tocador o el biombo como fórmulas de modernización, de vanidad y de prestigio -la cultura de las apariencias mandaba, y mucho. Los ojos, siempre vigilantes de novedades, instruían al cerebro sobre las adquisiciones a efectuar.

Se estimulaba la pulsión, por emulación de arriba hacia abajo, de gozar de ambos enseres, mobiliario doméstico al fin, de manera conjunta, cada uno en su estancia adecuada, pero simultáneamente. Los índices hallados lo patentizan, sin duda. El que la presencia de ambos al mismo tiempo evolucionara, en una óptica global, desde el $0.5 \%$ (1700-1721) al $3 \%$ (1781-1800) es apasionante. Empero, si observamos el comportamiento en las casas de los burócratas o de los nobles rentistas, sus porcentajes epatan. Los inductores de esta práctica fueron los nobles rentistas, quienes inician el siglo con un $4.2 \%$ de sus hogares con dicha circunstancia. Aumentaron, aunque con cierta vacilación, esa confluencia hasta el 12-15\%, para acabar el XVIII con un impresionante $21.4 \%$ de los hogares adaptados a ese formato modernizador. Los burócratas empezaron más tarde -con un 3.4 \% en 1721-1740-, desfallecen en 17411760 -probablemente como consecuencia de la disponibilidad de documentación-y llegan a su techo porcentual, en el entorno del $8 \%$, en 1761-1800. Es evidente que las demostraciones de exquisitez y de vanidad se fueron extendiendo por la ciudad, en la medida en que a unos y otros hogares llegaban las noticias de la implantación, aquí y allá, del tocador o del biombo, o de ambos simultáneamente.

$\mathrm{Si}$, además, en un alarde de curiosidad extrema, señalamos cuántos y qué hogares se habían dotado, en el Setecientos, de, al menos, un tocador, un biombo y un canapé, la respuesta a dichos interrogantes es categórica. En todos ellos encontramos también, entre otros enseres y pertrechos de exhibición y vanidad, relojes de faltriquera y cuberterías de plata. Ocho viviendas, es decir, el $50 \%$ de quienes simultaneaban tocador y biombo, disfrutaban también de canapé en sus estancias. El $37.5 \%$ eran burócratas de los más poderosos ${ }^{57}$ y el $62.5 \%$ eran nobles terratenientes y rentistas de entre la flor y la nata del Concejo burgalés ${ }^{58}$. Las poderosas

57 M. Espina de Velasco, viuda de Manuel de Haedo, mayordomo del Cabildo Catedral ( 558.590 1/2 reales de patrimonio libre). AHPB. Justicia Municipal. Alonso de Melo Peña. Legajo 987 (5 de mayo de 1780), folios 12-106 -, por una parte, y José Castilla y Portugal (121.406 reales de patrimonio libre) - AHPB. PN. José Guadilla. Legajo 7132 (30 de octubre de 1786), folios 525-569 - y José Antonio Gonzalo del Río (1.641.940 reales de patrimonio libre) - AHPB. PN. Nicolás Martínez de Vivanco. Legajo 7150 (3 de diciembre de 1768), folios 138-189 -, por otra, administradores general de la Administración de Rentas Reales - Hacienda borbónica -, por otra.

${ }^{58}$ Miguel de la Moneda (97.030 1/2 reales de patrimonio libre) - AHPB. PN. Santiago Romo. Legajo 6983 (21 de octubre de 1744), folios 133-148, Casilda Gallo (40.572 reales de patrimonio 
exigencias de la sociabilidad, y la disponibilidad de dinero en efectivo, lo demandaban y permitían ${ }^{59}$.

\section{A MODO DE CONCLUSIÓN}

La reconstrucción de la presencia de tocador y/o biombo en los interiores domésticos burgaleses en el siglo XVIII materializa, en la práctica, una visión entrometida en la intimidad de los hogares urbanos. El rastreo de canapés, relojes, vidrieras, cuberterías de plata, tocadores o biombos nos aproxima a una estratificación diferencial en una sociedad de Antiguo Régimen muy poco igualitaria. No todos tuvieron la posibilidad de disfrutar de un tipo de mobiliario que mejoraba sus prácticas higiénicas y de confort. Fuera por razones económicas o psico-sociológicas, e ideológicas, dar entrada al tocador y/o al biombo en sus estancias suponía conectar con Europa y con estrategias de habitabilidad progresivas y saludables. Los más pobres difícilmente dispusieron ni del dinero, ni del tiempo ni de la mentalidad adecuados como para implicarse en su disfrute. Tocador y biombo fueron aclimatados en las viviendas de los hogares con quehaceres profesionales menos dados al sufrimiento, a la fatiga laboral, hogares bastante acaudalados y encajados en los estamentos más privilegiados. Raramente se documentan tocadores y biombos entre aquellos que sufrían niveles de renta y de fortuna raquíticos. Los analfabetos y paupérrimos quizá ni se imaginaban qué era eso del tocador o el biombo.

El devenir creciente de su implantación inmiscuyó, en especial, a los aristócratas, a los militares, a los burócratas y a los comerciantes, es decir, a los más privilegiados y a los más cercanos a tendencias proto-burguesas. Es en los inventarios post-mortem en los que se detecta su introducción en las estancias de sus viviendas. Cuando en lo pormenorizado de su descripción, el escribano nos suministra información sobre las características de sus estancias, la documentación nos abre las puertas para visualizar, en la medida de lo posible, cómo el tocador y el biombo se desplegaban por las habitaciones de la casa. Muy pocos habían erigido una estancia

libre) - AHPB. PN. Francisco de Villafranca. Legajo 7096/1 (17 de enero de 1764), folio 20-41, Felipe Antonio Salamanca Moreda (157.719 1/2 reales de patrimonio libre) - AHPB. PN. José Guadilla. Legajo 7132 (8 de julio de 1782), folios 689-709, Cayetano de Arriaga (224.121 1/2 de patrimonio libre) - Archivo de la Diputación Provincial de Burgos. Fondo Berberana. José Arcocha. Legajo 107 (9 de julio de 1779), sin foliar y Antonio Fernández de Castro, marqués de Villacampo (403.088 reales de patrimonio libre) - AHPB. PN. José Guadilla. Legajo 7133/1 (11 de enero de 1788), folios 30-119.

${ }^{59}$ Cito, de manera circunstancial, varias propuestas de análisis que enmarcan un estudio de futuro sobre los paradigmas de vida y cultura material en el Burgos del XVIII y su imprescindible contraste con otras localidades de reconocida solvencia. Véanse, por ejemplo, Castañeda Peirón, 1984; Santiveri, 1986; Palos, 1988 y Sanz Yagüe, 2008. 
específica, denominada «Tocador» por lo que dichos muebles se desplegaban por las estancias de manera bastante polarizada. Predominaba el «Quarto» de segundo nivel por encima del "Quarto Principal» o del "Quarto de Estrado».

El tocador y el biombo eran, como el canapé, exquisitos bocados de lujo mobiliario, colocados en las entrañas de los interiores domésticos para estimular la sociabilidad o la intimidad, según el caso -aunque parezca paradójico. Eran muebles para mostrar a los invitados (tocador) o para ocultar escenarios íntimos a ojos indeseados (biombo). La confortabilidad y la exhuberancia se aunaban en un exclusivo puñado de hogares de una ciudad modesta preindustrial del Antiguo Régimen. No era la Corte, pero los hogares más poderosos y acaudalados se dotaban de muebles que les proyectaban hacia una sociedad más «burguesa», proto-capitalista, consumista y efervescente.

Queda para otras páginas, en el futuro, el análisis de las medidas de los tocadores y de los biombos. Además, es imprescindible generar una recreación pormenorizada, en aquellos inventarios que lo posibilitan, del entorno doméstico de las estancias en que los titulares de las casas burgaleses ubicaban el tocador y/o el biombo de que eran propietarios.

\section{REFERENCIAS BIBLIOGRÁFICAS}

Abad Zardoya, C. (2004). La vivienda aragonesa de los siglos XVII y XVIII. Manifestaciones del lujo en la decoración de interiores. Artigrama, 19, pp. 409425.

Abad Zardoya, C. (2007). Viejos modelos y nuevas costumbres: espacios privados para la mujer en la vivienda zaragozana del siglo XVIII. En R. M. Creixell, M. T. Sala y E. Castañer (Eds.), Espais interiors: casa i art. Des del segle XVIII al XXI (pp, 477-484). Barcelona: Universitat de Barcelona.

Ago, R. (2006). Il gusto delle cose. Una storia degli oggetti nella Roma del Seicento. Roma: Donzelli Editore.

Álvarez Santaló y García-Baquero García, A. (1980). La nobleza titulada en Sevilla, 1700-1833 (Aportación al estudio de sus niveles de vida y fortuna). Historia, Instituciones, Documentos, 7, pp. 3-6.

Angulo Morales, A. (2000). Del éxito en los negocios al fracaso del Consulado: La formación de la burguesía mercantil de Vitoria (1670-1840). Bilbao: Universidad del País Vasco. 
Arimura, R. (2007). El concepto de «privacidad» en Occidente y la función de los biombos y mamparas en el interior de la casa del conde de Xala en el siglo XVIII. Hispánica, 51, pp. 127-147. https://doi.org/10.4994/hispanica1965.2007.127.

Baena Zapatero, A. (2007). Nueva España a través de sus biombos. En F. Navarro Antolín (Ed.), Orbis Incognitud: avisos y legajos de Nuevo Mundo (pp. 441-450). Huelva: Universidad de Huelva.

Baena Zapatero, A. (2015). Apuntes sobre la elaboración de biombos en la Nueva España. Archivo Español de Arte, 350, pp. 173-188. https://doi.org/10.3989/ aearte.2015.11.

Bartolomé Bartolomé, J. M. (2017). Interiores domésticos y condiciones de vida de las familias burguesas y nobles de la ciudad de León a finales del Antiguo Régimen (1700-1850). León: Universidad de León.

Blasco Esquivias, B. (2006). La casa: Evolución del espacio doméstico en España. Madrid: Ediciones El Viso.

Braudel, F. (1984). Civilización material, economía y capitalismo. Siglos XV-XVIII. 1. Las estructuras de lo cotidiano. Madrid: Alianza Editorial.

Castañeda Peirón (1984). Ensayo metodológico sobre los inventarios post-mortem en el análisis de los niveles de vida material: el ejemplo de Barcelona entre 1790-1794. En Primer Congrés d'Història Moderna de Catalunya (Volumen I, pp. 757-769). Barcelona.

Crespo Rodríguez, M. D. (2006). Arquitectura doméstica de la Ciudad de los Reyes (1535-1750). Sevilla: CSIC, Universidad de Sevilla y Diputación de Sevilla.

Curiel, G. (1999). Los biombos novohispanos: escenografías de poder y transculturación en el ámbito doméstico. En G. Curiel, B. Navarrete e I. Leroy (Eds.), Viento detenido, mitologías e historias en el arte del biombo (pp. 9-32). Méjico: Museo de Soumaya.

Curiel, G. (2005). Ajuares domésticos. Los rituales de lo cotidiano. En P. Gonzalbo Aizpuru (Dir.), Historia de la vida cotidiana en México. Tomo II. La ciudad barroca. Méjico: Fondo de Cultura Económica.

Choi, J. (2018). La evolución del léxico del interiorismo desde el siglo XVIII hasta la primera mitad del siglo XX. Madrid: Universidad Complutense de Madrid. 
Dos Guimaraes, I. y García Fernández, M. (Dirs.). (2010). Portar adentro: comer, vestir, habitar (ss. XVI-XIX). Coimbra y Valladolid: Universidade de Coimbra y Universidad de Valladolid.

Echalecu, J. M. (1957). El mueble español en el siglo XVIII. Anales Españoles de Arte, 30, pp. 29-54.

Eleb-Vidal, M. y Debarre-Blanchard, A. (1989). Architectures de la vie privée. Maisons et mentalités, XVIIe-XIXe siècles. Bruxelas: Archives d'architecture moderne.

Ette, O. (2014). Muebles movibles y pintura en movimiento: los biombos y las fronteras ajustables de lo trasversal. Ibearoamericana, 54, pp. 85-95.

Franco, C. (2007). O mobiliario das elites de Lisboa na segunda metade do século XVIII. Lisboa: Livros Horizonte.

Franco Rubio, G. A. (2009). La vivienda en la España ilustrada: habitabilidad, domesticidad y sociabilidad. En O. Rey Castelao y R. J. López (Eds.), El mundo urbano en el siglo de la Ilustración. Santiago de Compostela: Xunta de Galicia.

Franco Rubio, G. A. (2012). El nacimiento de la domesticidad burguesa en el Antiguo Régimen. Notas para su estudio. Revista de Historia Moderna, 30, pp. 17-31. https://doi.org/10.14198/RHM2012.30.02.

Franch Benavent, R. (1989). El capital comercial valenciano en el siglo XVIII. Valencia: Universidad de Valencia.

García Fernández, M. (2012). Estancias y mobiliario doméstico multifuncional: alcobas y camas. En G. A. Franco Rubio (Ed.), La vida de cada día. Rituales, costumbres y rutinas cotidianas en la España moderna. Sevilla: Almudayna.

García Fernández, M. (2016). Desde la calle hacia mesas y alcobas. Privacidades materiales domésticas de Antiguo Régimen entre los grupos populares, intermedios y burgueses. Tiempos Modernos, 32, pp. 398-418.

González Heras, N. (2014). Servir al rey y vivir en la corte: propiedad, formas de residencia y cultura material en el Madrid borbónico. Madrid: Universidad Complutense de Madrid.

López Castán, A. (2004). La ebanistería madrileña y el mueble cortesano del siglo XVIII. Anuario del Departamento de Historia y Teoría del Arte, 16, pp. 129-150. 
López Pérez, M. P. (1999). El objeto de uso en las salas de las casas de habitación de españoles y criollos en Santafé de Bogotá. Anales del Instituto de Investigaciones Estéticas, 74-75, pp. 99-134. https://doi.org/10.22201/ iie.18703062e.1999.74-75.1870.

Madureira, N. L. (1992). Cidade: Espaço e quotidiano (Lisboa, 1740-1830). Lisboa: Livros Horizonte.

Mantecón Movellán, T. (2013). España en tiempos de Ilustración. Los desafíos del siglo XVIII. Madrid: Alianza Editorial.

Martínez Alcázar, E. (2011). Los espacios públicos de las viviendas acomodadas del siglo XVIII a partir de la documentación notarial de Murcia y Madrid. Atrio, 17, pp. 91-102.

Martínez Alcázar, E. (2008). El mueble en la vivienda murciana a finales del siglo XVIII: una visión a través de la documentación notarial. Imafronte, 19-20, pp. 219-232.

Mateos Gil, A. J. (2007). La vivienda de don José Raón Cejudo en Calahorra a partir del inventario de sus bienes (1799). Kalakorikos, 12, pp. 197-246.

Moreno Claverías, B. (2003). Pautas de consumo y diferenciación social en El Penedés a fines del siglo XVII. Una propuesta metodológica a partir de inventarios sin valoraciones monetarias. En E. Llopis, J. Torras y B. Yun (Eds.), El consumo en la España pre-industrial, Revista de Historia Económica, n.o extraordinario, pp. 230-232. https://doi.org/10.1017/S021261090001082X.

Moreno Claverías, B. (2007). Consum i condicions de vida a la Catalunya Moderna. El Penedès, 1670-1790. Vilafranca del Penedès: Edicions i Propostes Culturals Andana.

Moreyra, C. E. (2009). Vida cotidiana y entorno material. El mobiliario doméstico en la ciudad de Córdoba a fines del siglo XVIII. Historia Crítica, 248, pp. 122-144. https://doi.org/10.7440/histcrit38.2009.07.

Nadal Iniesta, J. (2006). El mobiliario doméstico en la Murcia de principios del siglo XVIII (1700-1725). Imafronte, 18, pp. 93-103. 
Ojeda San Miguel, R. (1988). Ropas y mobiliario en las casas de Miranda de Ebro [Burgos] durante los siglos XVII y XVIII. Instituto Municipal de Historia, 17, pp. 25-51.

Ordóñez Goded, C. (2016). De lacas y charoles en España: siglos XVI-XIX. Madrid: Universidad Complutenses de Madrid.

Ortego Agustín, M. A. (2009). Discursos y prácticas sobre el cuerpo y la higiene en la Edad Moderna. Cuadernos de Historia Moderna, 8, pp. 67-92.

Palos, J. L. (1988). Vivir en Barcelona. Sugerencias para una conceptualización de la élite ciudadana en los siglos XVI-XVII. Manuscrits, 7, pp. 262-283.

Pardailhé-Galabrun, A. (1988). La naissance de l'intime. 3000 foyers parisiens. XVIIeXVIIle siècles. París: Presses Universitaires de France.

Pichardo Hernández, A. O. (2009). Pintura y vida cotidiana: un biombo del siglo XVIII en Nueva España. Acatlán, 4, pp. 29-38.

Piera Miquel, M. (2006a). La cómoda y el tocador, muebles de prestigio en la sociedad catalana del siglo XVIII. Pedralbes, 25, pp. 266-282.

Piera Miquel, M. (2008). Los artesanos del mueble en Barcelona a finales del siglo XVIII: el espacio doméstico. Nuevo Mundo Mundos Nuevos [En línea], Coloquios (2008). http://nuevomundo.revues.org/index27542.html. https:// doi.org/10.4000/nuevomundo.27542.

Piera Miquel, M. (2009a). Quan s'és jove per fer bonic i quen s'és gran per no fer fàstic. Tocadores y lavamanos en la vivienda catalana de la época moderna. Cuadernos de Historia Moderna, 8, pp. 93-117.

Piera Miquel, M. (2009b). Muebles de ebanistería en las viviendas de Barcelona. En M. Piera, A. Shelly y J. Marsal (Dirs.), El mueble del siglo XVIII: Nuevas aportaciones a su estudio (pp. 63-74). Barcelona: Ajuntament de Barcelona.

Piera Miquel, M. (2009c). Cómodas y otros muebles de importación en los interiores domésticos barceloneses del siglo XVIII. En O. Rey Castelao y R. López (Eds.), EI mundo urbano en el siglo de la llustración (pp. 371-383). La Coruña: FEHM.

Pounds, N. J. G. (1999). La vida cotidiana. Historia de la cultura material. Barcelona: Crítica. 
Ramos Palencia, F. (2010). Pautas de consumo y mercado en Castilla, 1750-1850. Economía familiar en Palencia al final del Antiguo Régimen. Madrid: Sílex.

Ramos Palencia, F. (2016). Révolution industrielle, identité et effect trickle-down dans une économie sous-développée: le «monde des couleurs» dans una petite province castillane (Palencia), 1750-1850. En Consommateurs \& consommation: XVIIe-XIXe siécle: regards franco-espagnols (pp. 47-77). Persignan: Presses Universitaires de Perpignan. https://doi.org/10.4000/books.pupvd.4747.

Rodríguez Bernis, S. (2009). Nuevas maneras, nuevos muebles. En M. Piera, A. Shelly y J. Marsal (Dirs.), El mueble del siglo XVIII: Nuevas aportaciones a su estudio (pp. 33-42). Barcelona: Ajuntament de Barcelona.

Rodríguez Bernis, S. (2010). Damas en estuches, damas en el tocador. Moda e interiores femeninos en la España del siglo xVIII. En El arte en el siglo de las luces (pp. 431-458). Madrid: Galaxia Gutenberg.

Sánchez-Cascado, F. (2106). Biombos, algo más que un mueble. [en línea] Tiovivo creativo, http://www.tiovivocreativo.com/mobiliario/biombos-algo-mas-queun-mueble.

Santiveri (1986). Clases sociales y niveles de vida material en la Lleida del siglo XVII (1644-1700). Manuscrits, 3, pp. 129-149

Sanz de la Higuera, F. (2013). Aproximación al devenir del canapé en los interiores domésticos burgaleses del XVIII. Cuadernos de Historia Moderna, 38, 139-161. https://doi.org/10.5209/rev_CHMO.2013.v38.42639.

Sanz de la Higuera, F. (2019). «Canapeses» en los interiores domésticos en el Burgos del Setecientos. Cuadernos de Investigación Histórica, (en fase de evaluación).

Sanz Yagüe, A. I. (2008). Patrimonio, cultura material y diferenciación social en la ciudad de Soria durante el siglo xVIII. En Nuevo Mundo Mundos Nuevos [En línea], Coloquios (2008). http://nuevomundo.revues.org/index22902.html. https://doi.org/10.4000/nuevomundo.22902.

Sarti, R. (2002). Vida en familia. Casa, comida y vestido en la Europa moderna. Barcelona: Crítica. 
Sobrado Correa, H. (2003). Los inventarios post-mortem como fuente privilegiada para el estudio de la historia de la cultura material en la Edad Moderna. Hispania, 215, pp. 825-862. https://doi.org/10.3989/hispania.2003.v63.i215.207.

Waro-Desjardins, F. (1992). La vie quotidienne dans Le Vexin au XVIIle siècle. Dans I'intimité d'une société rurale. Condé-sur-Noireau: Editions du Vallhermeil.

Yun Casalilla, B. (1999). Inventarios post-mortem, consumo y niveles del campesinado del Antiguo Régimen. Problemas metodológicos a la luz de la investigación internacional. En J. Torras y B.Yun (Dirs.), Consumo, condiciones de vida y comercialización. Cataluña y Castilla, siglos XVII-XIX. Ávila: Junta de Castilla y León. 